\title{
Flexible SERS substrates for hazardous materials detection: recent advances
}

\author{
Moram Sree Satya Bharati and Venugopal Rao Soma*
}

This article reviews the most recent advances in the development of flexible substrates used as surface-enhanced Raman scattering (SERS) platforms for detecting several hazardous materials (e.g., explosives, pesticides, drugs, and dyes). Different flexible platforms such as papers/filter papers, fabrics, polymer nanofibers, and cellulose fibers have been investigated over the last few years and their SERS efficacies have been evaluated. We start with an introduction of the importance of hazardous materials trace detection followed by a summary of different SERS methodologies with particular attention on flexible substrates and their advantages over the nanostructures and nanoparticle-based solid/hybrid substrates. The potential of flexible SERS substrates, in conjunction with a simple portable Raman spectrometer, is the power to enable practical/on-field/point of interest applications primarily because of their low-cost and easy sampling.

Keywords: hazardous materials; flexible; surface-enhanced Raman scattering (SERS); nanomaterials; nanostructures Bharati MSS, Soma VR. Flexible SERS substrates for hazardous materials detection: recent advances. Opto-Electron Adv 4, 210048 (2021).

\section{Introduction}

In the present-day scenario, human health, and environmental safety are the foremost concerns worldwide. Hazardous materials are referred to as those which have been determined to be capable of presenting an unreasonable risk to human health, safety, and property. The main characteristics of these materials are ignitability, corrosivity, reactivity, or toxicity. The specific categories among these materials are explosives, flammable liquids, gases, oxidizers, corrosives, flammable solids, radioactive materials, poisonous/infectious substances, and dangerous substances. We start with a short overview of various hazardous materials followed by the introduction of Raman spectroscopy and surface enhanced Rama spectroscopy/scattering (SERS) techniques. This review aims to report on the detection of hazardous materials such as explosives, pesticides, and simulants of chemical warfare agents using flexible SERS substrates.

\section{Hazardous materials}

Explosives/high energy materials (HEMs) are those materials that contain nitro groups (which are energetic) and release an enormous amount of energy in the form of light and heat when they are subjected to an external stimulus such as (a) spark (b) shock or even (c) friction. Explosives are commonly categorized as primary and secondary depending on their detonation (velocity, pressure etc.) and sensitivity parameters. Primary explosives are extremely sensitive and release enormous energy even with a small perturbation such as shock/collision. Therefore, the difficulty is generally high while handling the primary explosives. They act as boosters or initiators for detonating secondary explosives. Lead azide and mercury fulminate are a few examples of primary explosives, while 1,3,5,7-Tetranitro-1,3,5,7- tetrazocane (HMX), 1,3,5-Trinitroperhydro-1,3,5-triazine (RDX), trinitrotoluene (TNT), etc. are representative of

Advanced Centre of Research in High Energy Materials (ACRHEM), University of Hyderabad, Telangana 500046, India.

*Correspondence: VR Soma, E-mail: soma_venu@uohyd.ac.in

Received: 10 April 2021; Accepted: 18 July 2021; Published online: 25 October 2021

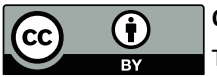

Open Access This article is licensed under a Creative Commons Attribution 4.0 International License.

To view a copy of this license, visit http://creativecommons.org/licenses/by/4.0/.

(C) The Author(s) 2021. Published by Institute of Optics and Electronics, Chinese Academy of Sciences. 
secondary explosives secondary explosives secondary explosives seconda. Interestingly, there are few home-prepared explosives utilized in the preparation of improvised explosive devices (IEDs). These are now easily synthesized at the laboratory level from simple molecules such as ammonium nitrate (AN), dinitrotoluene (DNT), picric acid (PA), etc.. Pesticides are the chemicals used by farmers/transporters to protect the crops/vegetables/ fruits from insects/pests/rodents. The overused pesticides will remain as residues in the food, which may cause risk to human health (cancer/allergies/intoxications) and the ecosystem (surface water/soil) ${ }^{2}$. Malathion, Carbofuran, methyl parathion, Carbaryl, etc., are a few examples of various pesticides available in the market. For example, thiram is the most used pesticide, which averts fungal diseases, but it causes damage to the skin and is very harmful to the health. Chemical warfare agents (CWAs) ${ }^{3,4}$ are the chemical weapons used in a terrorist attacks, which are an intensified threat to the environment and civilian population. The principal compounds are mustard, lewisite, G-series nerve agents [Tabun (GA); Sarin (GB); Soman (GD)], and V-series nerve agents [O-ethyl S-(2-diisopropylaminoethyl) methylphosphonothioate (VX)]. Sarin was used as a chemical weapon by terrorists in the 1995 exposure incident in the Tokyo subway system wherein more than 1000 people were affected. At room temperature, these are volatile liquids that cause a serious risk (paralysis, loss of consciousness, depression of the central respiratory drive) from exposure (dermal contact with a liquid nerve agent). Inhalation of the low vapor nerve agent even for a few minutes (for e.g., $\sim 10 \mathrm{~min}$ ) causes the contraction of the pupils of the eye, tightness of the chest, headache, rhinorrhea, etc ${ }^{3}$. These are extremely toxic, and their usage is restricted in non-surety laboratories because of the risk in exposure assessments. Chemical warfare agent simulants are recently developed, and they mimic the actual CWAs carrying all the relevant chemical and physical properties without accompanying their toxicological properties. Vinod Kumar et $\mathrm{al}^{5}$. reported the development of CWAs, their toxicity, and first usage as weapons worldwide. He discussed the different principles and chemical sensing methods of CWAs and developments in chromo-fluorogenic sensing techniques. Most of the CWA simulants are odorless, colorless, and tasteless. Distilled mustard (HD- $\mathrm{C}_{4} \mathrm{H}_{8} \mathrm{Cl}_{2} \mathrm{~S}$ ), methyl salicylate (MS- $\mathrm{C}_{8} \mathrm{H}_{8} \mathrm{O}_{3}$ ), 2-Chloroethyl methyl sulphide (CEMS- $\mathrm{C}_{3} \mathrm{H}_{7} \mathrm{ClS}$ ), etc. are the surrogate simulants of mustard CWA. Dimethyl methylphosphonate (DMMP), di-ethyl methylphosphonate (DEMP), di-ethyl ethylphosphonate (DEEP), Diisopropyl methylphosphonate (DIMP), etc. are the simulants of G-Agent. [G-Agent named because these are first secretly synthesized by the German Ministry of Defense before and during World War II-1936] Amiton (VG), S-diethyl phenylphosphonothioate (DEPP), Malathion, parathion, etc. are simulants of VX agent.

Therefore, rapid and reliable detection of these hazardous molecules is the primary concern of both governmental agencies and research community to reduce the risk to society. Razdan and co-workers ${ }^{6}$ have recently provided a comprehensive review on the laser based standoff detection of CWA. In this review, they clearly tabulated the classification, toxicity (lethal dose), and other important properties of the CWA. The significant global research progress in the laser-based sensors such as Raman sensors and DIAL [differential absorption LIDAR (light detection and ranging)] sensors in the detection of CWA. There exists a variety of analytical methods (reported in the literature) for the detection of such hazardous materials either in residue/bulk form or in concealed places. Some of the tested and mature techniques include ion-mobility spectroscopy (IMS), terahertz (THz) spectroscopy, laser-induced breakdown spectroscopy (LIBS), Raman spectroscopy and variants, photo-acoustic, and gas chromatography, etc ${ }^{7-14}$. Some of these techniques either cause partial sample destruction or require isolation of sample, which is very difficult in the case of traces. Additionally, a few of these techniques do not favor the usage of low quantity samples and require a skilled person for instrument calibration and measurements. Furthermore, high water absorption, poor specificity, and difficulty in instrumentation limit the usage of these techniques for on-field explosive detection $^{15,16}$.

\section{Raman spectroscopy and variants}

Raman spectroscopy is a simple, rapid, and a non-destructive spectroscopic technique based on molecular vibrations as signatures in the spectra. The Raman spectrum of any analyte molecule provides specific information and conveys chemical/structural information. This is important in the case of explosives (in pure form or even in the mixture form) irrespective of solid, liquid, powder, or gas state ${ }^{17-22}$. However, Raman scattering is a very weak process and, consequently, requires either 
large quantities of the analyte or high input laser powers to obtain the molecular signatures. Surface-enhanced Raman scattering is one of the advanced and developed Raman techniques for overcoming these limitations (intrinsically low Raman signal intensity for low concentration of the analyte molecules) ${ }^{1}$. This is based on the huge electric field enhancements in the vicinity of nanostructured metals resulting in a strong Raman signal.

In the present times, flexible SERS substrates have received great interest due to them possessing the advantages of (a) easy sampling by swabbing/wrapping directly on any curved/rough surfaces (b) large scalability by printing/roll to roll manufacturing/electrospinning etc. and (c) low overall cost of the sensing system. The development of handy flexible substrates with compact Raman devices/smart-phones can possibly provide portable sensors in real-world sensing/safety applications and serve as a powerful analytical tool for on-field analysis. For example, the possibility of detection of ultralow concentrations [picomolar $\left(10^{-12} \mathrm{M}\right.$ or $\left.\mathrm{pM}\right)$ to femtomolar $\left(10^{-15} \mathrm{M}\right.$ or $\left.\left.\mathrm{fM}\right)\right]$ of two nerve gases, $\mathrm{VX}$ and Tabun was reported recently by Hakonen et $\mathrm{al}^{23}$. using flexible $\mathrm{Au}$ covered Si nanopillars (SERS substrates) and, significantly, using a handheld Raman spectrometer. Furthermore, the time involved in a typical detection can be reduced to practically acceptable levels $(<5 \mathrm{sec})$ using these portable and low-cost disposable SERS substrates.

\section{Surface-enhanced Raman scattering (SERS)}

Martin Fleischmann and co-workers had reported a fortunate discovery way back in 1974, in which they observed enhanced Raman signals of a pyridine molecule adsorbed on an electrochemically roughened silver surface ${ }^{24}$. They reported the enhancement in the Raman cross-section of pyridine vibrations by a factor of $\sim 106$. This enhancement of the Raman signal in the vicinity of the metal nanostructure was named "surface-enhanced Raman scattering." In the year 1977, Van Duyne ${ }^{25}$ and Albrecht ${ }^{26}$ groups separately explained the mechanism of enhanced Raman signals from the metal surface. In 1985, Moskovits et $\mathrm{al}^{27}$. reported all the primary explanations for the enhancement mechanisms such as (a) electromagnetic (EM) enhancement and (b) chemical (CM) enhancement. The long-range EM enhancement is attributed to the so-called localized surface plasmon resonance (LSPR) in the near-field metallic surface. The interaction of the incident EM field with metal NPs possess- ing negative real and small positive imaginary (absorption) dielectric constant induces a collective and coherent electron oscillations, called plasmons, in the vicinity of the NP or nanostructure (NS). The interaction of electromagnetic (EM) fields with the NPs affect their optical properties which are prevailed by the material's dielectric constant at the excitation wavelength and also the surrounding media. The plasmonic noble-metal materials (mainly Au and Ag) exhibits high SERS activity because of their LSPR in the visible region, and the materials such as aluminum $(\mathrm{Al})$, gallium $(\mathrm{Ga})$, platinum $(\mathrm{Pt})$ palladium (Pd), titanium (Ti), bismuth (Bi), indium (In), rhodium $(\mathrm{Rh})$, and ruthenium $(\mathrm{Ru})$, etc. exhibit the plasmonic resonance in the deep ultraviolet (UV) region ${ }^{28}$. Several review articles presented throughout this review discussed the significance of various optical materials used in SERS studies. The short-range CM enhancement is due to the charge transfer mechanism between the analyte molecule and the substrate ${ }^{29}$. Noble-metal-free SERS materials, for example semiconductors ( $\mathrm{Si}, \mathrm{GaAs}$ and etc.) and two-dimensional (2D) layered materials ${ }^{30,31}$ $\left(\mathrm{MoS}_{2}\right.$, graphene, HBN and etc.) exhibit the $\mathrm{CM}$ enhancement. Usually, Raman signals of the molecules can be enhanced by $10^{4}$ to $10^{10}$ times because of the large EM enhancements supported and provided by the plasmonic nanostructures in close proximity $(\sim 1 \mathrm{~nm})$. The CM enhancement is at least 2-3 orders of magnitude less than that of EM enhancement. During the last two decades, several scientists have extensively studied the effective parameters influencing the enhancement of the SERS signal $^{32,33}$. Enhancements in the Raman signal is a result of several contributions and it is virtually difficult to separate them into distinct components. Several factors including the platform, SERS active material, analyte properties, excitation laser mainly affect the enhancement of the Raman signals and are illustrated and explained as a schematic in Fig. 1.

\section{Reviews on different SERS studies}

A variety of review reports on SERS have been published over the last decades addressing the issues concerned with fabrication techniques, applications, and their developments. For example, Fan et $\mathrm{al}^{34}$. reviewed the various fabrication studies of SERS substrates such as electron-beam lithography, focused ion beam (FIB) milling, and also template-based techniques. The advantage of these nanostructured substrates is the fine control over 




Fig. 1| A schematic depicting the various parameters influencing the SERS signal.

the nanostructured geometries, which provide high reproducibility in the intensity of SERS signals. They discussed the application of those solid SERS substrates in biosensing, environmental, and optical fiber sensing. Mahadeva et al. ${ }^{35}$, in the year 2015, reviewed the applications of paper as sensors in different fields like electronic devices, biosensors, strain sensors, gas sensors, and piezoelectric devices. Further, their limitations in the commercialization of these devices were also discussed. Muehlethaler et $\mathrm{al}^{20}$. summarized (in the year 2016) the forensic applications of SERS in the detection of explosive vapors, CWA simulant, fire accelerants, gunshot residues, etc. Mosier-Boss et $\mathrm{al}^{18}$. reviewed the properties of metallic SERS substrates and their usage towards the detection of various molecules such as drugs, pesticides, explosives, BTEX (benzene, toluene, ethylbenzene, xylenes), dyes, cations, and anions. Furthermore, they addressed the usage of commercially available SERS substrates. Restaino et $\mathrm{al}^{36}$. (2018) reviewed the point of interest sample detection using flexible and porous SERS substrates. They described the various fabrication techniques with different sample collection methods and highlighted the unprecedented ease of use of the paper sensors. Senthamizhan et $\mathrm{al}^{37}$. reviewed the developments of the different electrospun nanofibers (metal oxide nanofiber, composite fibers) and their use as glucose sensors in the year 2016. Hakonen et $\mathrm{al}^{38}$. reviewed (in the year 2015) the trends and perspectives of the SERS substrates in the detection of explosives and chemical warfare agents. Ogundare et $\mathrm{al}^{39}$. reviewed extensively the cellulose-based SERS platforms including their funda- mentals, fabrication approaches, and application in the detection of various probe molecules. Recently, Maddipatla et $\mathrm{al}^{40}$. reviewed the recent approaches and the future opportunities in the development of flexible sensors in the food, environmental, and defense fields. Sun et $\mathrm{al}^{19}$. reviewed the on-site application of SERS by the combined portable Raman spectrometer and SERS substrates (the year 2020). The choice of an appropriate substrate is extremely essential in the SERS measurements. The requirements of an ideal SERS substrate for practical applications are a) sensitivity (able to detect very low concentrations of analyte molecules), b) uniformity (similar SERS signal strength over the entire substrate), c) reproducibility (similar data should be obtained from measurements spanning different batches, time periods etc.), d) recyclability (should be able to detect different analyte molecules with a single substrates by simple cleaning and to reduce the cost of SERS substrates), e) stability (SERS signal should not fall drastically over a period of few weeks, at least), f) flexibility (should be able to collect samples from uneven surfaces), as well as g) low fabrication cost (ideally SERS substrates should cost less since the Raman spectrometer cost is very high). A schematic of key points of SERS substrates requirements is illustrated clearly in the Fig. 2. Each of these factors and their significance are discussed in detail in the next section.

Sensitivity is the biggest virtue of a good SERS substrate is the detection of molecules at very low concentrations [traces meaning parts per billion (ppb) or parts per trillion (ppt) or parts per quadrillion (ppq)]. The 


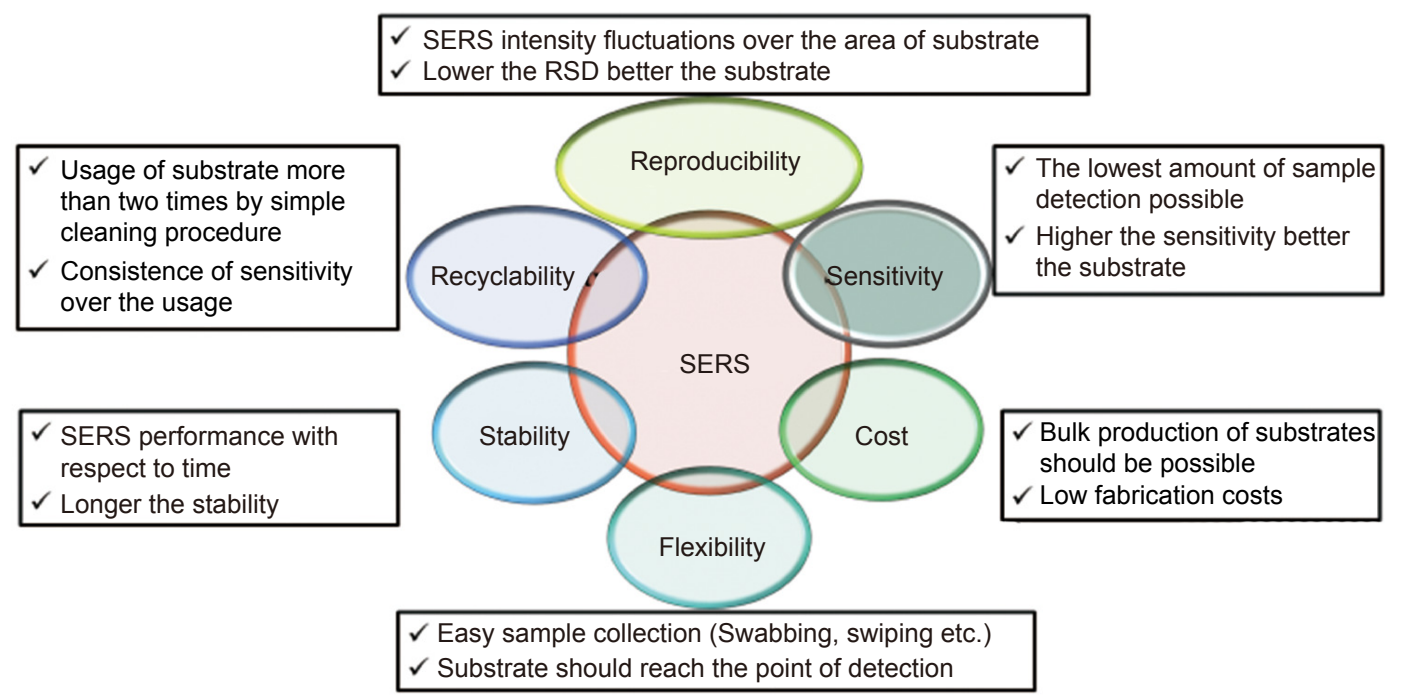

Fig. 2 | The ideal requirements of SERS substrates are summarized in this schematic.

sensitivity is generally expressed in terms of the lowest quantity of probe molecule detection possible with a given SERS substrate. The Raman signal disappears when the molecule concentrations reach a limit value. The sensitivity of the SERS substrate varies from molecule to molecule. The sensitivity of the SERS substrate is typically represented by the enhancement factor (limit of detection for a particular vibration mode of the probe molecule). Therefore, one should be judicious with the SERS substrate and select one with a higher enhancement factor or a lower limit of detection (LOD) over a wide range of analytes. Reproducibility is related to the variation of SERS intensity of the probe molecule over the NS surface. The smaller the variation in the signal, the higher the reproducibility and it is generally reported in terms of RSD (relative standard deviation) of the SERS signal. This depends mainly on the distribution of hotspots on the substrate. Low reproducibility of any SERS substrate affects the potential usage in practical applications. It is highly challenging to produce a highly reproducible SERS platform along with a homogeneous distribution of hotspots. The fluctuations of the SERS signals are calculated statistically with RSD of the particular mode intensity in the SERS spectrum. The magnitude of $\% \mathrm{RSD}$, indicative of the coefficient of variation, provides uncertainty in the measurement. Lower RSD values indicate a superior substrate in terms of reproducibility. Recyclability is another essential factor to test the usage of the same SERS substrate after detecting one/two molecules followed by proper cleaning procedures ${ }^{41}$. Xu et $\mathrm{al}^{42}$. developed recyclable hedgehog-shaped $\mathrm{CuO}$
$\mathrm{NWs} / \mathrm{Cu}_{2} \mathrm{O}$ hetero NSs (with Ag coating) as SERS substrates. These hetero NS have demonstrated strong SERS activity ( $85 \%$ retained after 7 cycles of usage) driven by a broad band visible-light photocatalytic degradation process. $\mathrm{Ag} / \mathrm{CuO} \mathrm{NWs} / \mathrm{Cu}_{2} \mathrm{O}$ composites were fabricated by ns laser ablation and subsequent thermal oxidation on the $\mathrm{Cu}$ sheet to develop $\mathrm{Cu}$ NWs on the grooved surface which was subsequently followed by Ag NPs deposition. The recyclability measurements were performed with the MG molecule by demonstrating seven-times consistent SERS performance. Stability is related to the variation of the sensitivity of SERS substrate with respect to time. This aging effect for the SERS substrates is also another important factor for storage in air/vacuum for days/months/year and their performance afterwards. Finally, the fabrication cost of the substrates is very important for the bulk production and commercialization of substrates for regular usage. Despite the long history of SERS, flexibility garnered much interest only recently because of easy sample collection from any uneven surface by simple swabbing/swiping etc. Producing uniform, stable, and highly sensitive SERS substrates has been a major obstacle for real-field applications. Therefore, the main task for the SERS community has been to develop the substrates with high sensitivity/reproducibility, long stability, low cost, and easy to handle, as well as flexible for sample collection.

The important results from the literature survey over the last 5-10 years concerning the usage of flexible SERS substrate for various hazardous materials detection is also summarized in this article. A large number of 
papers have been published in this area. To demonstrate the magnitude of research, a simple search for papers published in the journals and conferences, including the title/keywords/abstract "flexible Surface Enhanced Raman Spectroscopy" or "flexible Surface Enhanced Raman Scattering" or "flexible SERS" as indexed by the Scopus search engine, resulted in typically $>100$ papers in 2019, >100 papers in 2020 and $>40$ in the year 2021 alone. The corresponding data obtained is plotted as a bar graph and is shown in Fig. 3. The identification of all the developments and practical applications of flexible SERS studies in various fields will be difficult to be presented in this review. Therefore, we have acknowledged the most important recent review articles and those are listed in the Table 1 below. The readers are suggested to select and pursue the review based on their interest(s). This review is limited to the recent studies (typically during the last 3-4 years) on flexible SERS substrates used in the detection of hazardous materials, rather than including broad discussions on solid SERS substrates (nanostructures on solid targets and metal NPs suspension on the solid platform) and their develop- ments, which is a huge field. This review is warranted because of the extremely rapid developments in the area of different nanomaterials synthesized (for SERS studies including plasmonic and non-plasmonic), novel methodologies developed for incorporating various nanoparticles in different flexible platforms, and detection of diverse analyte molecules.

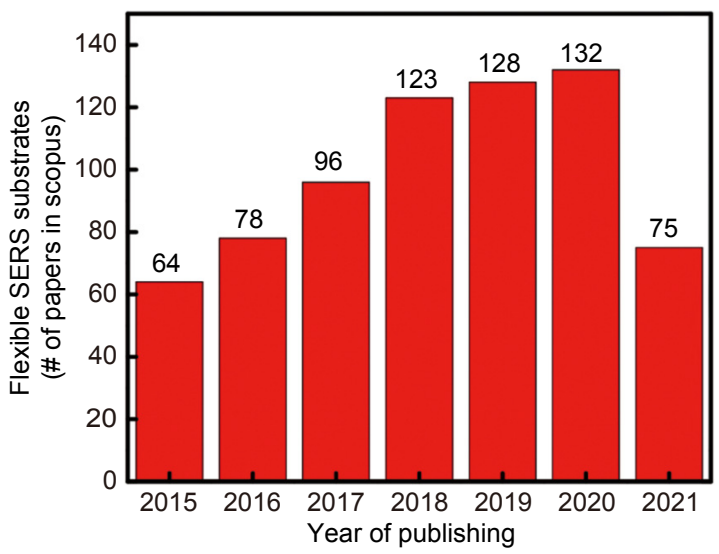

Fig. 3 | Year wise publications on flexible SERS substrates obtained through a search in SCOPUS.

Table 1 | Important review articles on various applications of SERS that have been reported in the last three-years (2019-2021).

\begin{tabular}{|c|c|c|c|}
\hline S. No. & Author & Review topic & Ref. \\
\hline 1 & Zhang et al. & Flexible SERS substrates and recent advances in food safety analysis & ref. ${ }^{43}$ \\
\hline 2 & Yin et al. & Recent process of $2 \mathrm{D}$ materials in SERS & ref. $^{30}$ \\
\hline 3 & Klapec et al. & $\begin{array}{l}\text { 2016-2019 published literature on the forensic related molecules and their various detection } \\
\text { techniques using SERS }\end{array}$ & ref. 44 \\
\hline 4 & Li et al. & Fabrication and applications of flexible, transparent SERS substrates & ref. 45 \\
\hline 5 & Forbes et al. & Developed and challenges of SERS sensor in the detection of inorganic based explosives & ref. ${ }^{46}$ \\
\hline 6 & Ji Sun et al. & $\begin{array}{l}\text { SERS substrate developments and combination with other technologies in on-site analysis using } \\
\text { portable Raman spectrometer }\end{array}$ & ref. ${ }^{19}$ \\
\hline 7 & Jingjing et al. & Different dimensional (OD, 1D, 2D and 3D) SERS substrates for explosive detection & ref. 47 \\
\hline 8 & Shvalya et al. & $\begin{array}{l}\text { Plasmonic NPs and 3D plasmonic NSs sensors with biological, medical, military, and chemical } \\
\text { applications }\end{array}$ & ref. $_{.}^{48}$ \\
\hline 9 & To et al. & Explosive trace detection technologies and latest advances & ref. ${ }^{49}$ \\
\hline 10 & Ren et al. & Qualitative and quantitative analysis; strategies of practical application of SERS substrates & ref. ${ }^{50}$ \\
\hline 11 & Huang et al. & Paper SERS substrates in food safety & ref..$^{51}$ \\
\hline 12 & Chen et al. & 2D SERS substrates in chemical and biosensing & ref. $^{52}$ \\
\hline 13 & Dinesh et al. & Flexible sensor fabrication with various printing techniques & ref. ${ }^{40}$ \\
\hline 14 & Xue et al. & Flexible nanofiber-based substrates fabrication and application & ref. $^{53}$ \\
\hline 15 & Ogundare et al. & Cellulose-based SERS substrates: fundamentals and principles & ref. $^{39}$ \\
\hline 16 & Zamora Sequeira et al. & Various methods for the determination of pesticides & ref. $^{2}$ \\
\hline 17 & Piolt et al. & Key aspects of SERS and application in the biomedical field & ref. ${ }^{54}$ \\
\hline 18 & Ogundare et al. & Cellulose substrate fundamental, preparation methods, and applications & ref. ${ }^{39}$ \\
\hline 19 & Lee et al. & Analyte manipulation and hybrid SERS platforms for real-world applications & ref. ${ }^{55}$ \\
\hline 20 & Xu et al. & $\begin{array}{l}\text { Latest advances of flexible SERS substrates in point of care diagnostic in tunable, sample } \\
\text { swapping and in-situ SERS detection highlights }\end{array}$ & ref. $^{56}$ \\
\hline 21 & Zhang et al. & Electrospinning NPs based material and their sensing application & ref. $^{57}$ \\
\hline 22 & Restaino et al. & Plasmonic paper SERS substrates-preparation methods and sample collections & ref. 36 \\
\hline
\end{tabular}




\section{Flexible SERS substrates}

A forthright method to achieve the SERS-active substrates is to dry the colloidal NPs (preferably plasmonic) solution on any of the glass/silicon/paper/metal surfaces. ${ }^{1}$ Depending on the platform where these NPs/NSs are deposited, the SERS substrates can be classified as either rigid or flexible. Rigid SERS substrates are accomplished via deposition of colloidal solutions on the surface of the glass or silicon or metal sheet and patterned glass/silicon/metal sheets [e.g., metal-insulatormetal structures $\left.\mathrm{Au}-\mathrm{SiO}_{2}-\mathrm{Au}^{59}\right]$. Alternatively, flexible SERS platforms can be achieved from the usage of cellulose papers, textiles, thin films, polymers, adhesive tapes $^{60-64}$, etc. Both rigid and flexible SERS substrates have their exclusive advantages and disadvantages. Solid SERS substrates usually display better recyclability, signal homogeneity, and higher enhancement factors. However, the cost and sample collection have a considerable impact on daily practical usage of any SERS substrate. Apart from the detection of molecules, flexible substrates have potential in several applications such as fabrication of electronic devices ${ }^{65}$ (diodes, transistors, energy storage devices, etc.), food safety ${ }^{66}$, cancer screening $^{67}$, and pathogens multiplex detection ${ }^{68}$, uric acid in human tears ${ }^{69}$.

The capabilities of flexible SERS substrates have gained tremendous research interest due to

- Inexpensive fabrication procedures making it possible to prepare large area substrates.

- Easy-to-use nature for on-site detection of a wide range of probe molecules.

- Flexibility in sample collection, i.e., possible to collect the probe molecules/sample directly from any rough surface (e.g., suitcase, bag, table surface, fruit, etc.) with the substrate by simple swabbing/swiping.

The merits of the SERS technique with the portable Raman spectrometer now widely used in national security, food safety, and environmental monitoring.

Recently explosives detection was approached by fabricating various flexible SERS substrates. Liyanage et $\mathrm{al}^{58}$. synthesized flexible SERS sensors with an adhesive film (Scotch magic-tape) loaded with Au triangular nanoprisms by simple self-assembly method as shown in Fig. 4. The estimated LOD of TNT, RDX, and PETN was $\sim 900, \sim 50$, and $\sim 50$ ppq (parts per quadrillion), respectively. Furthermore, they have also demonstrated direct sampling detection of TNT which was collected from fingerprints by simple swabbing of samples which were

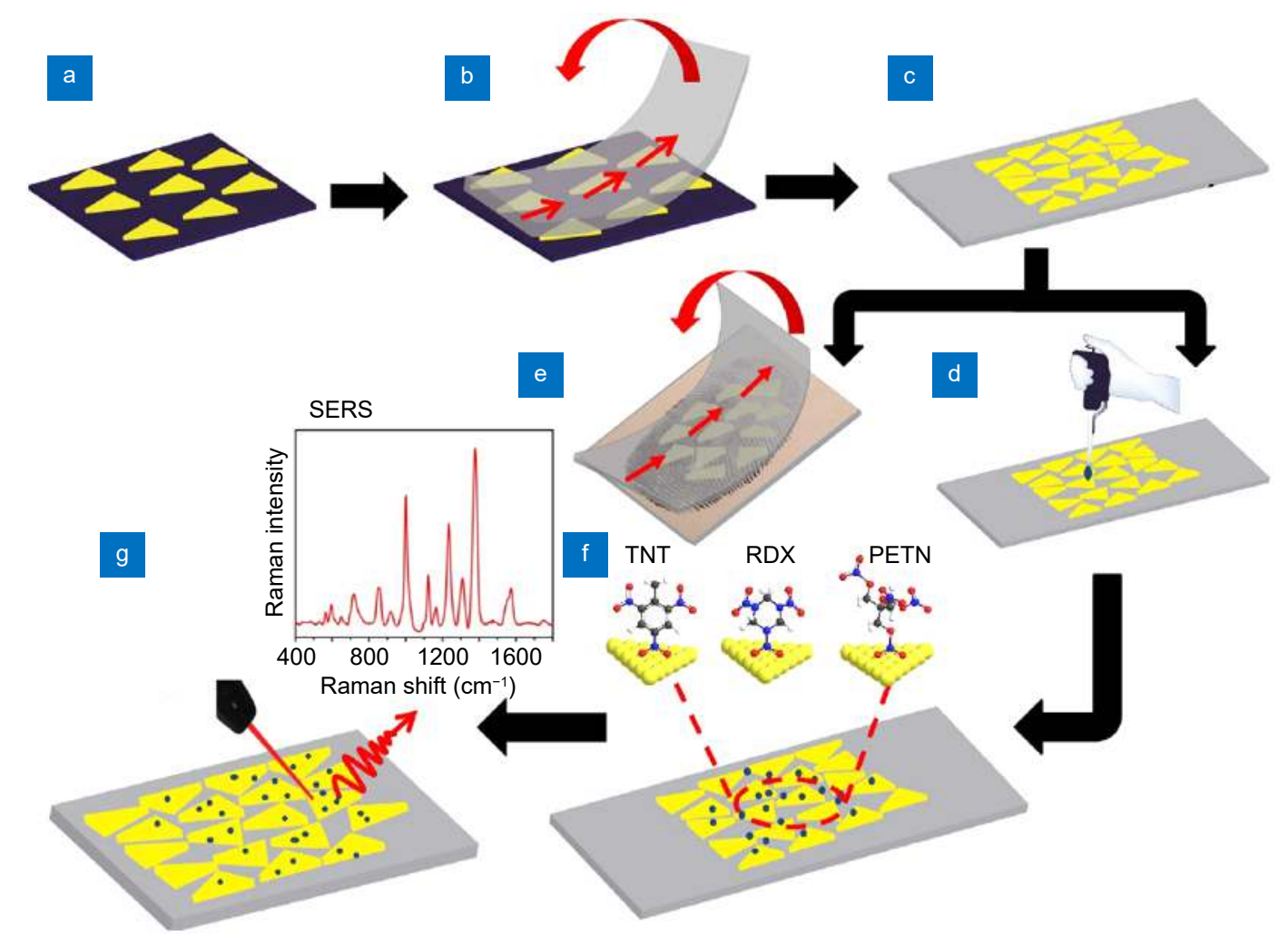

Fig. 4 | Explosive trace detection using flexible SERS substrates detection of TNT, RDX, and PETN using self-assembly triangular nanoprisms on adhesive tape. Figure reproduced with permission from ref. ${ }^{58}$, Royal Society of Chemistry. 
prepared by placing the thumb onto a series of 10 glass slides. And they successfully proved these flexible SERS substrates have the stability with a "shelf life" of at least 5 months. Gao et $\mathrm{al}^{70}$. synthesized light trapping wrinkled nanocones $(50-60 \mathrm{~nm})$ flexible SERS substrates using colloidal (polystyrene microspheres-1 $\mu \mathrm{m}$ ) lithography and oxygen plasma etching (5 minutes) on polyethylene terephthalate (PET) film followed by $30 \mathrm{~nm}$ gold film by electron beam deposition. The optimized wrinkled nanocone 4-ATP labelled flexible substrate was used to detect four explosive molecules RDX, HMX, PETN, and TNT. The TNT residue collection and SERS spectra of TNT residues from the cloth bag by bended to brush collection is followed by $5 \mathrm{~min}$ immersion in 4-ATP-labelled AgNPs.

\section{Paper-based SERS substrates}

A detailed literature survey revealed that a variety of papers were used (as a base material) for preparing the SERS substrates such as filter paper $^{71}$, chromatography paper $^{72}$, A4 sized paper $^{73}$, tissue papers ${ }^{74}$, and different GCM grade papers ${ }^{75}$. The porosity of the paper (which is typically a few $\mu \mathrm{m}$ ) will affect the retention of NPs on its surface. There are numerous approaches for the fabrication of paper-based SERS substrates reported in recent literature including physical vapor deposition ${ }^{76,77}$, dipping method ${ }^{67,71}$, in-situ growth of metal $\mathrm{NPs}^{78,79}$, hydrophilic wells by wax printing followed by drop-casting of the $\mathrm{NPS}^{80}$, pen-on-paper technique ${ }^{73}$, inkjet printing ${ }^{72,81}$, etc.. Some of these techniques of the fabrication of paper substrates, collated from a few recent research reports, is illustrated in Fig. 5. The in-situ synthesis implies soaking of a cellulose paper in metal salts such as $\mathrm{AgNO}_{3} / \mathrm{HAuCl}_{4}$ in conjunction with reducing agents (such as $\mathrm{NaBH}_{4} /$ citric acid/Tollens agent). These methods later require additional processing such as heating/plasma treatment/rinsing/cleaning. Therefore, these synthesis procedures need multiple cycle processes $^{82-84}$. Dip coating is a unpretentious method in which the NPs have to be first synthesized, then the NPs are deposited on to the paper. However, the NPs loading depends on the absorbance and soaking time of the paper (a comprehensive discussion on the above techniques is provided in ref. ${ }^{1}$ ). Several recent studies have demonstrated the utility of different approaches for improving the loading [e.g., prior soaking of paper in $\mathrm{NaCl}$, Glycidyl-trimethyl-ammonium chloride (GTAC) $]^{85,86}$. The advantage of dip coating/immersion method is its ability to deposit NPs with different shapes, sizes, and compositions on the paper ${ }^{87-89}$. Another popular fabrication method is the inkjet/screen printing, which is a simple method of deposition of NPs on paper using a commercial desktop inkjet printer. The efficacy of the SERS substrate depends on the designing of substrate patterns, which is to preserve the viscosity and surface tension of the NPs ink, and printing cycles to upsurge the density of NPs. Inkjet printing offers easy-to-design complex geometries using a personal computer and it is feasible to print already prepared NPs (by laser-based or chemical methods) and in-situ synthesis is also possible by loading precursor agents in different color ink cartridges $^{90}$. Furthermore, to improve the SERS substrate efficiency and to avoid unwanted spreading of NPs, hydrophobic modification of paper has been exploited before the printing of $\mathrm{NP}^{91}$.

Kim et $\mathrm{al}^{92}$. used a silicon rubber mask ( $3 \mathrm{~mm}$ diameter and $1 \mathrm{~mm}$ thickness) to construct SERS sensor arrays. Gold nanorods (AuNR, L/D: 44 $\pm 2 / 10 \pm 1 \mathrm{~nm}$ ) were dispersed on top of RC cellulose with vacuum-assisted filtration method on each well on RC hydrogel. The SERS activity and these AuNR array film was examined as a function of the AuNRs volume (8, 10, 12 and $14 \mu \mathrm{L})$ and different drying times (1,2, 3 and 24 hours), and better SERS activity is noticed for $12 \mu \mathrm{L}$ with increasing drying time. These SERS arry demonstrated the simultaneous detection of multiple hazardous chemicals such as R6G (10 pM), RB, CV, 4-ATP, BPE, thiram (100 fM), tricyclazole, difenoconazole, and mancozeb. And the Multi-SERS spectra of thiram are recorded from each AuNR array on RC film. [i) $10 \mu \mathrm{M}$; ii) $1 \mu \mathrm{M}$; iii) $100 \mathrm{nM}$; iv) $10 \mathrm{nM}$; v) $1 \mathrm{nM}$ ]. And also, bending cycle tests were conducted for 500 times. These results show good sensitivity, stability and repeatability of low-cost flexible SERS substrates. Li Xian et al $^{93}$. fabricated cellulose nanocrystal-Ag NPs embedded filter paper SERS substrate via in situ reduction. These $\mathrm{CNC}-\mathrm{Ag}$ paper substrates were modified by soaking in dodecyl mercaptan at different concentrations ranging from $10^{-4}$ to $10^{-18} \mathrm{~g} / \mathrm{mL}$. The concentration was optimized as $10^{-12} \mathrm{~g} / \mathrm{mL}$ by performing contact angle and SERS measurements. Finally, the optimized SERS substrate was used to detect phenylethanolamine A and metronidazole with a LOD of $5 \mathrm{nM}$ and $200 \mathrm{nM}$. Lan et $\mathrm{al}^{74}$. reported the inkjet-printed paper-based semiconducting $\left(\mathrm{MoO}_{3-x}\right)$ SERS substrates to detect CV and MG on the fish surface by swabbing. Previously, our group presented a systematic study ${ }^{94}$ on the 


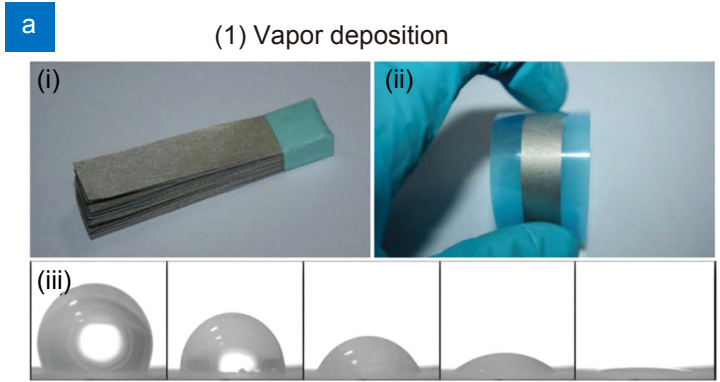

c

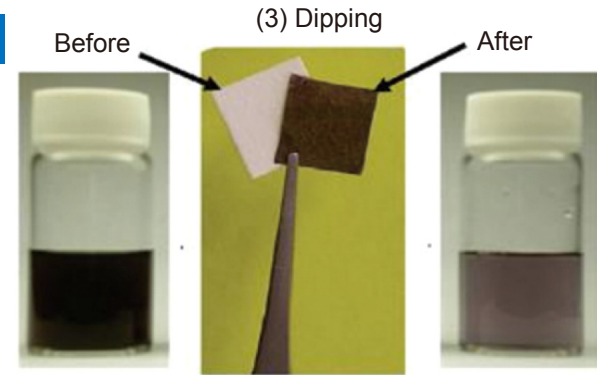

d

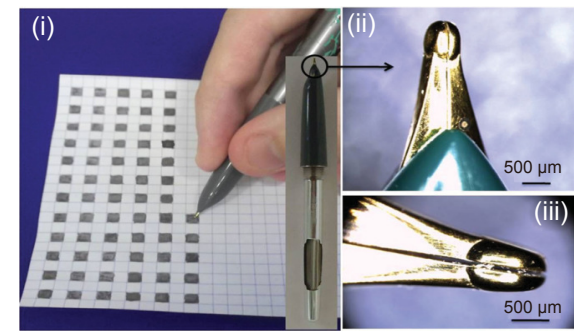

(6) Self-assembling

f

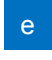

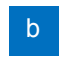

(2) Inkjet printing
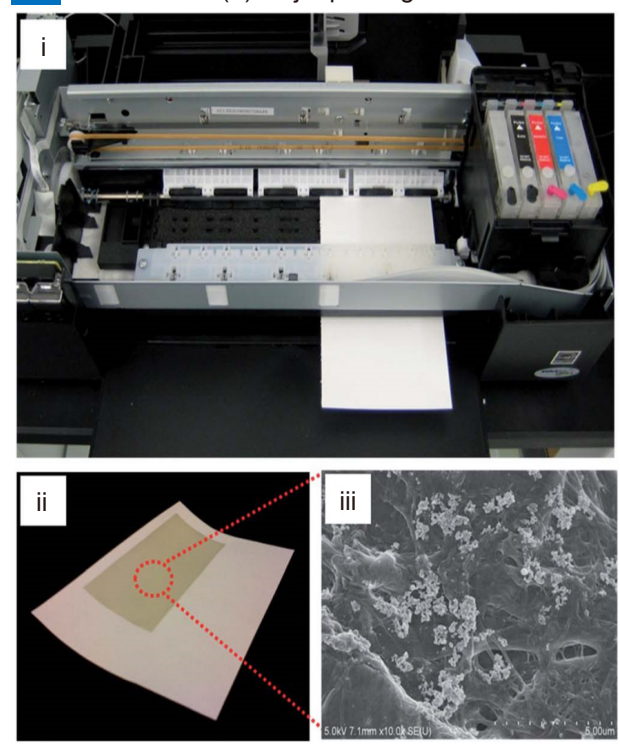

(5) Drop casting

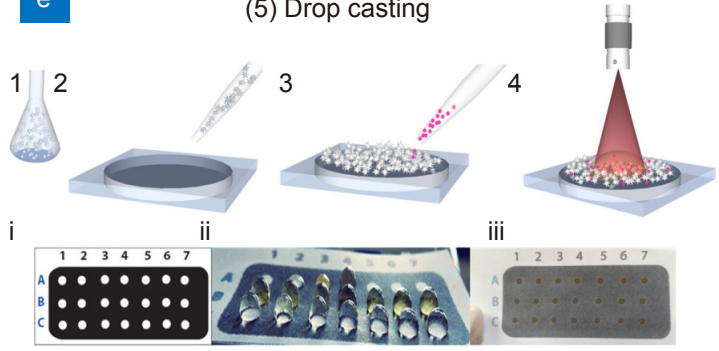

g

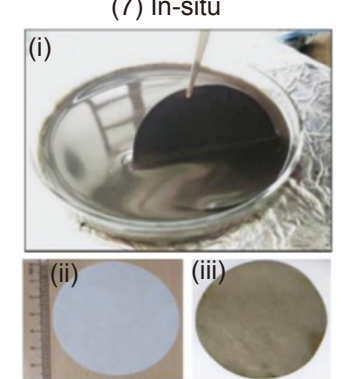

Fig. 5 | Various fabrication techniques used for paper-based SERS substrates. (a) Vapor deposition. (b) Inkjet printing. (c) Dipping. (d) Penon-paper. (e) Drop-casting on hydrophilic wells. (f) Self assembling. (g) In-situ reduction. Figure reproduced with permission from: (a) ref. ${ }^{77}$, (b) ref. $^{72}$, The Royal Society of Chemistry; ref. ${ }^{71}$, American Chemical Society; (d) ref. ${ }^{73}$, John Wiley and Sons; (e) ref. ${ }^{80}$, Springer Nature; (f) ref. ${ }^{84}$, (g) ref. ${ }^{79}$, American Chemical Society.

fabrication of versatile low-cost FP flexible SERS substrates loaded with salt-induced aggregated Ag/Au NPs. The SERS substrates were subsequently prepared by soaking the FP in aggregated NPs by simple addition of different concentrations of $\mathrm{NaCl}$ (1 to $100 \mathrm{mM}$ ). The detailed SERS measurements were indicated that the $\mathrm{Ag} / \mathrm{Au} \mathrm{NPs}$ with $50 \mathrm{mM} \mathrm{NaCl}$ concentration is the optimal SERS performance. This optimized FP with aggregated $\mathrm{Ag} / \mathrm{Au}$ NPs were used detect four adsorbed mo- lecules MB-5 nM, PA-5 $\mu \mathrm{M}$, DNT-1 $\mu \mathrm{M}$, and NTO-10 $\mu \mathrm{M}$ using portable Raman spectrometer. The schematic of FP SERS preparation (a) the SEM image of FP (b) without and (c) with NPs and the SERS spectra of explosive molecules (right side) are shown in Fig. 6.

Lin et $\mathrm{al}^{95}$. reported the PDMS assisted paper based SERS platform for the on-site monitoring of food safety. Firstly, Au@Ag nanorods (NRs) are synthesized using seed mediated growth, and are deposited on filter paper 



Fig. 6 | Filter paper based SERS substrate by aggregated Ag/Au NPs for explosive molecule detection (Left side) (a) schematic of substrate preparation (b) and (c) FESEM images of bare filter and aggregated Ag NPs (Right side) SERS spectra of (a) PA (b) DNT (c) NTO using FP with optimized aggregated Ag NPs. Figure reproduced with permission from ref. ${ }^{94}$, American Chemical Society.

through self-assembly technique. Finally, dual functional SERS platform was made via side of the paper with the NPs affixed onto PDMS using polymethyl methacrylate (PMMA) tape, as the schematic shows in Fig. 7(a). The SERS platform optimized by Au@Ag NRs with 1 to 6 layers were also assembled on the filter paper, and SERS measurements $(\mathrm{CV})$ demonstrated that the Raman intensity of the probe molecule gradually decreases as the number of layers increases. The optimized monolayer SERS paper-based PDMS-assisted platform was used to detect thiram $(0.75 \mathrm{ppm})$ on the surface of orange by just simple wiping and the presence of PDMS enables higher performance with better sensitivity of SERS. Further, various concentrations of thiram on orange surface (from $0.5 \mathrm{ppm}$ to $50 \mathrm{ppm}$ ) and the concentration versus intensity Langmuir adsorption for the Raman spectra are shown in Fig. 7(b).

\section{Polymer-based SERS substrates}

\section{Nanofiber mats}

Electrospinning is a method of translation of polymeric solution/melt (with or without additives) into solid nanofibers by applying the electric field ${ }^{1}$. The electrospun nanofiber films are identical to paper substrates in many aspects. For example, they have similar flexibility, porosity, and a high surface area. Moreover, their morphology, thickness, porosity, etc. (of the nanofiber films) can be varied by judiciously choosing the experimental parameters (i.e., solution parameters, process parameters, and ambient parameters $)^{53,96-98}$. The concentration of polymer solution being used demonstrates an essential role in the electrospun fiber fabrication. At very low concentrations of the polymer solution, electrospraying occurs instead of electrospinning. Therefore, micro/nanodroplets are deposited on the collector drum. With a slight increase in polymer solution concentration, a mixture of microbeads and fibers has been observed". Smooth nanofibers are observed at an appropriate concentration depending on the polymer molecular weight. If the concentration is too high, nanofibers will not be formed, and only micro-ribbons will be observed ${ }^{1}$. Therefore, with an increase in the concentration of the polymer solution, the obtained fiber diameter will increase. Usually, the viscosity and surface tension of the solution can be modified by altering the concentration of the used polymer. At a very low viscosity or surface tension, continuous and smooth fibers cannot be attained. If the viscosity of the polymer solution is very high, it results in the hard ejection of polymer jet from the syringe 


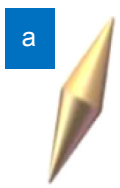

$\underset{60^{\circ} \mathrm{C}}{\stackrel{\mathrm{AgNO}_{3}}{\longrightarrow}}$

Au NBPs

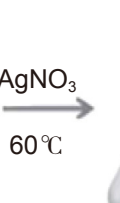

Au@Ag NRs
Self-assembly

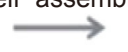

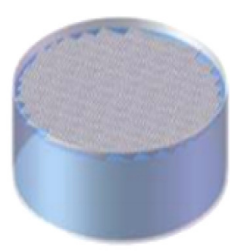

Monolayer

on the interface

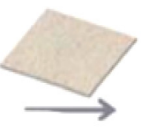

Filter paper

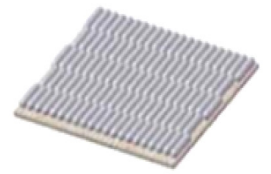

Deposited on paper

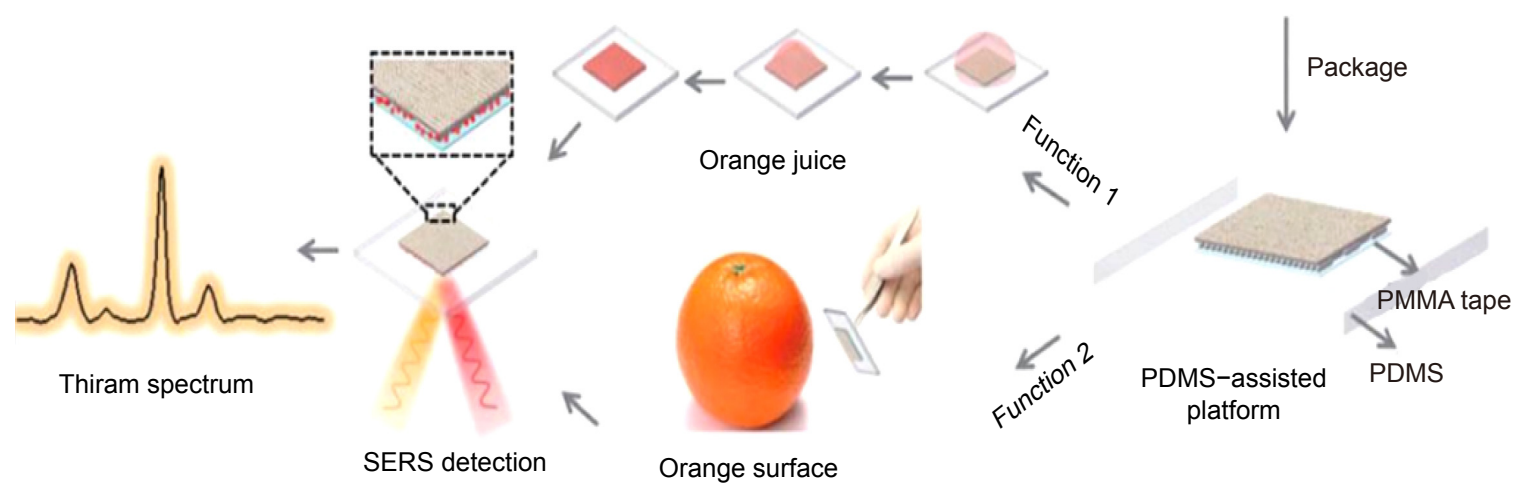

b
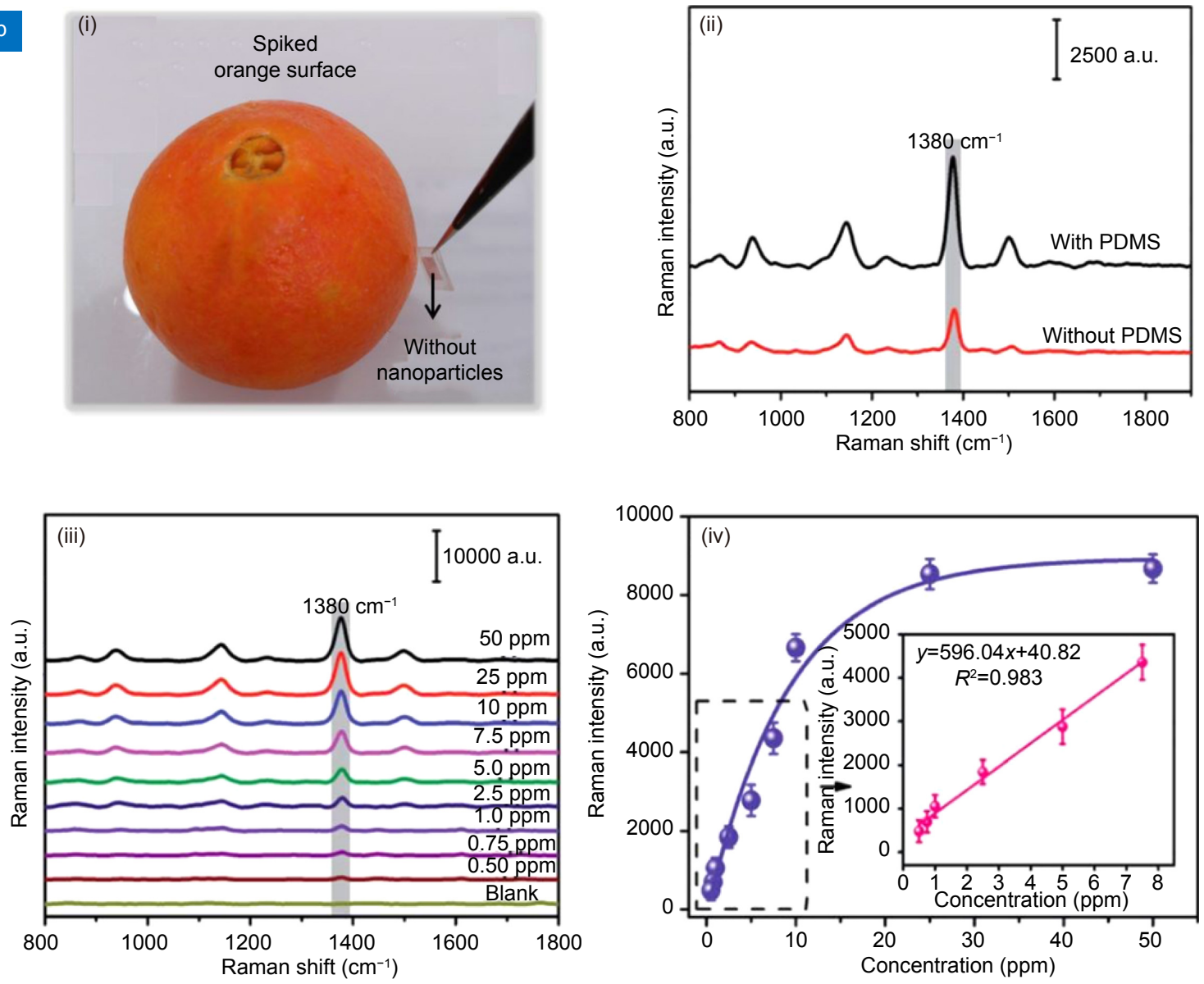

Fig. 7 | (a) A schematic of the synthesis of dual-functional PDMS-assisted paper-based SERS platform. (b) (i) The photograph of a sample collection from orange surface. (ii) A comparison of SERS spectra of CV with and without PDMS. (iii) SERS spectra of different concentrations of thiram (0.5-50 ppm). (iv) The peak intensity at $1380 \mathrm{~cm}^{-1}$ of thiram in orange juice as a function of the spiked sample concentration. Figure reproduced with permission from ref. ${ }^{95}$, Royal Society of Chemistry. 
needle. The polymer molecular weight also affects the fiber morphology as a decrease in the molecular weight tends to form more beads rather than smooth fibers. $\mathrm{Hu}-$ sain et al ${ }^{19}$. analyzed the fiber morphology of PLGA [poly (lactic-co-glycolic acid)] in acetone with a varying concentration between 2 and $25 \mathrm{wt} \%$. At low concentration (2-4 wt\%), a mixture of particles and beads-on strings are observed, and at high concentration (20-25 wt\%), only fibers are obtained. The fiber morphology can be tuned with the processing parameters such as the applied voltage for the electrostatic force, flow rate, nozzlecollector distance, fiber collector humidity, and temperature, etc. Recently, Wan et al. ${ }^{100}$ reported $\mathrm{SiO}_{2}$ electrospun nanofiber loaded with $\mathrm{Ag} / \mathrm{Au}$ nanoparticles SERS substrate with high sensitivity $-10^{-11} \mathrm{~mol} / \mathrm{L}$, stability -60 days, repeatability for various molecules (S. aureus, thiram, 4-MPh, and 4-MPA), and the schematic is illustrated in Fig. 8.

The SERS performance of nanofiber depends on the properties of

- nanofibers (polymer nature, fiber diameter, the morphology of the nanofibers, and spinning time, etc.) and

- nanoparticles ${ }^{101}$ (material type, size, shape, composition, and density), etc.

- Decoration of NPs on the fiber ${ }^{102,103}$ (within the fiber, the surface of the fiber, etc.)

- The loading of NPs on the nanofiber mat leads to the NPs assembly with extremely small spacing providing scope for abundant hot spots. These play a crucial factor in SERS response.

Electrospinning polymer fibers can be used as SERS substrates by loading plasmonic NPs; similar to paper substrates, several methods are reported for embedding metal NPs onto the electrospun polymer films like dispersion of metal precursor and pre-mixing of metal NPs into the polymer solution and surface medications after electrospinning. Chamuah et $\mathrm{al}^{104}$. demonstrated the $\mathrm{Au}$ deposition after electrospinning PVA nanofiber. Recently, Motamedi et a ${ }^{105}$. added laser-ablated Au NPs in Polyvinylidene fluoride (PVDF) solution before electrospinning. Zhang et al ${ }^{106}$. performed different trials on the addition of $\mathrm{Au}$ nanorods in the PVA solution before electrospinning. Zhang et $\mathrm{al}^{107}$. have performed a detailed study on fabrication of electrospun nanofibrous surface decorated with Ag NPs. Amidoxime surfacefunctionalized polyacrylonitrile (ASFPAN) nanofibrous membranes surface-decorated with Ag NPs using electrospinning followed by the seed-mediated electroless plating. A series of SERS substrates were prepared by altering the reaction time (1, 2, 3, 4 and 5 minutes) and stirring conditions (stirring and non-stirring) during the electroless plating deposition of Ag NPs. The change in the size, shape, and aggregation of Ag NPs on the surface of nanofibrous membrane and their effect on SERS efficiency were evaluated. The best SERS sensitivity was noticed for ASFPAN-Ag NPs nanofibrous membrane at 3 minutes under non-stirring condition, the corresponding reflectance, SEM and TEM images shown in Fig. 9. These optimized SERS substrates detect 10 ppb R6G and 4-MBA.

Recently flexible polymer-based (PDMS ${ }^{108}$, PMMA $^{109}$, PET $^{110}$, PVDF ${ }^{11,112}$, etc.) SERS substrates have gained interest from various research groups. Wang et $\mathrm{al}^{113}$. have synthesized the sandwiched Au@Ag NPs [between
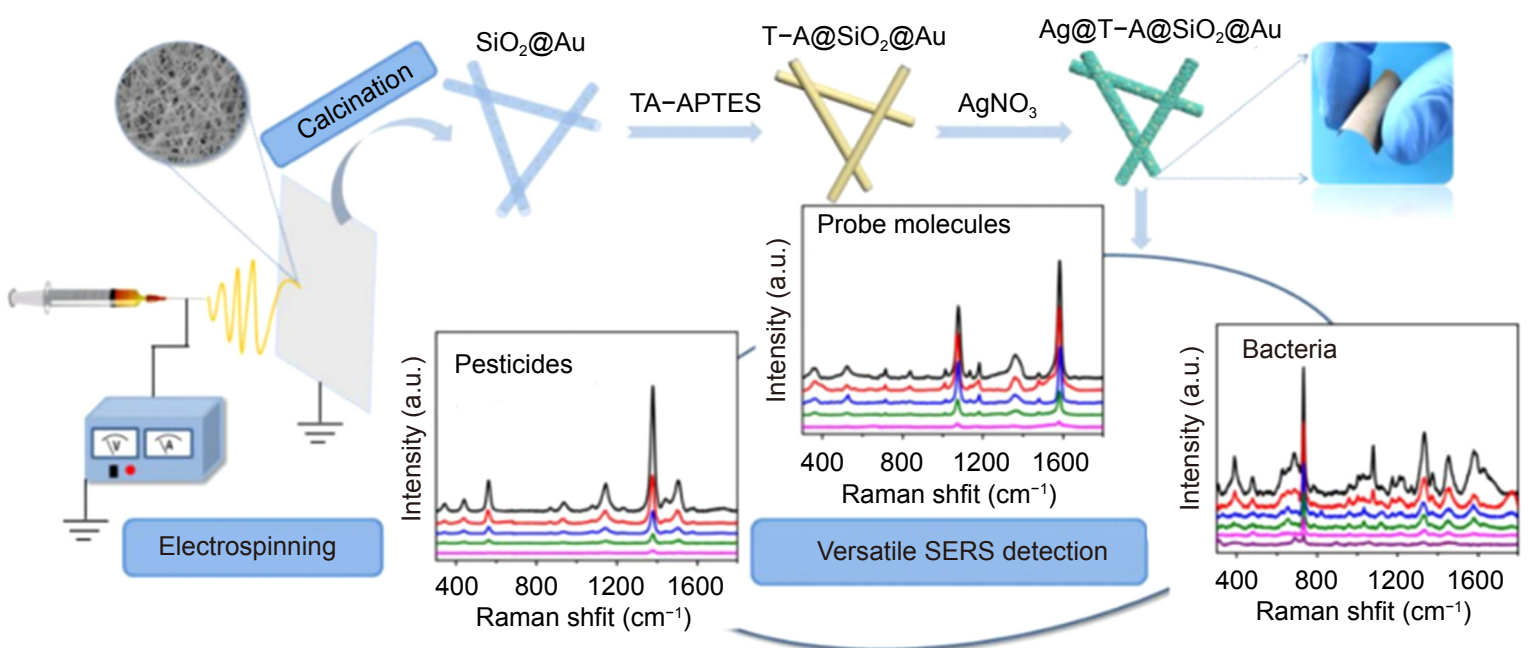

Fig. 8 | Fabrication of flexible SERS substrates for Ag@T-A@SiO2-Au nanofibrous substrates. Figure reproduced with permission from ref. ${ }^{100}$, under a Creative Commons Attribution 4.0 International License. 

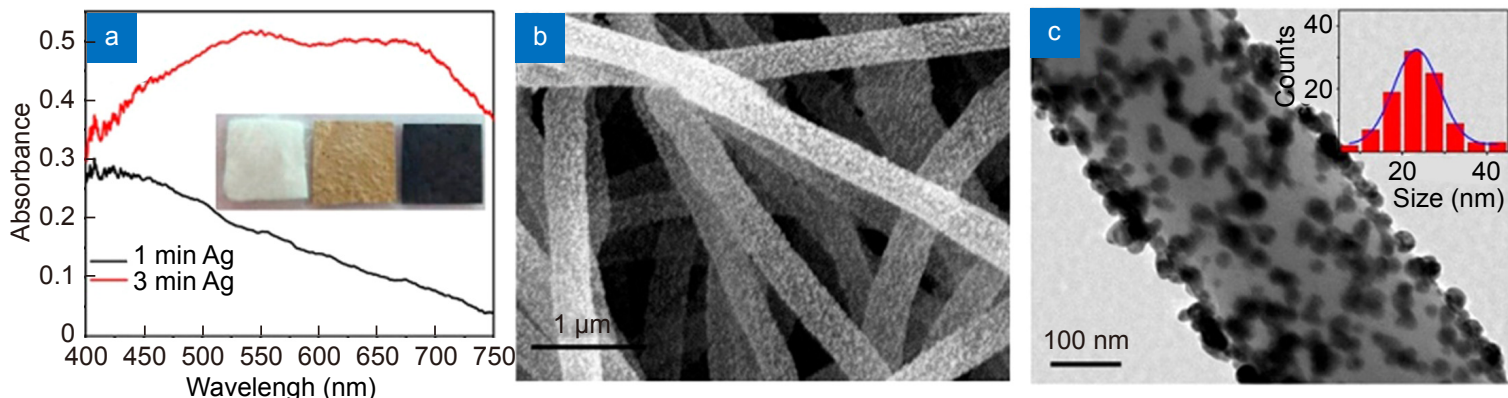

Fig. 9 | (a) Reflectance spectra of the ASFPAN nanofibrous membranes with Ag NPs; Photographs of three nanofibrous membranes (PAN, ASFPAN, and ASFPAN-Ag NPs) are shown in the inset. (b) SEM image and (c) TEM image of ASFPAN nanofibers (3 min). Inset in (c) shows the size distribution of Ag NPs. ${ }^{107}$, American Chemical Society.

adhesive acrylic polymer tape and polyethene terephthalate (PET)] film using the self-assembly method. Here, PET film was used to protect the Au@Ag NPs array from environment for long-term stability (60 days). While performing the SERS measurements, the protection PET film was peeled off carefully, and the T/Au@Ag substrate was utilized for sensing CV-1 nM with a LOD of $\sim 9 \times 10^{-10} \mathrm{M}$. These flexible T/Au@Ag substrates were further investigated for realistic applications like thiram residues extracted from the peel of apple, tomato, and cucumber. Zhang et $\mathrm{al}^{114}$. reported low cost large area high-throughput nanostructured polymer flexible SERS substrate, the schematic shown in Fig. 10(a). These were prepared in three steps (1) preparation of anodic aluminum oxide (AAO) mold (2) formation of polymer nanostructure using roll-to-roll ultraviolet $(365 \mathrm{~nm}$,

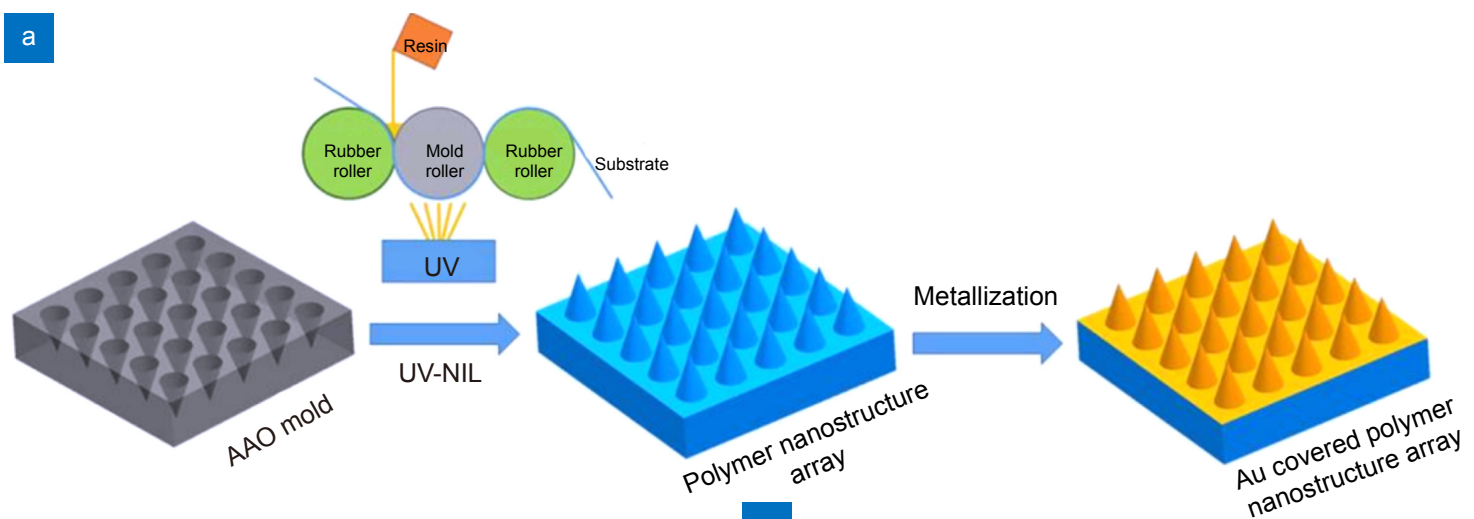

b



c

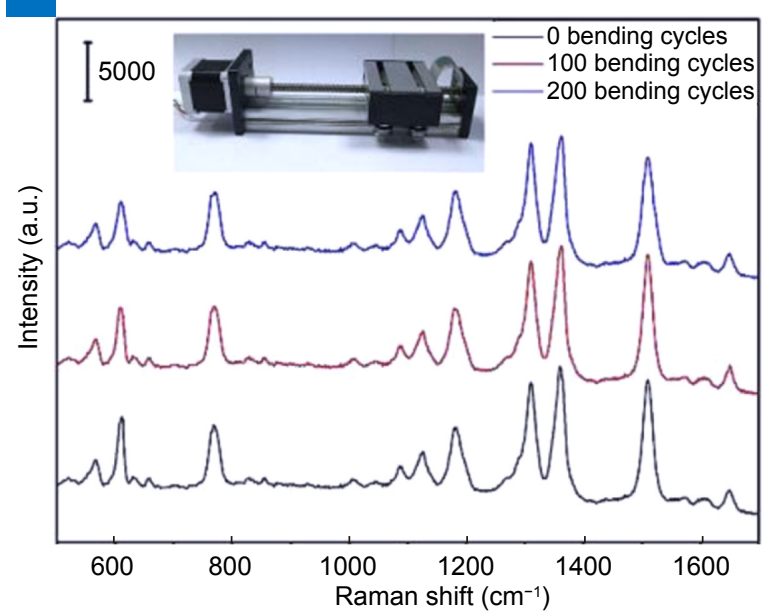

Fig. 10 | (a) Schematic diagram representing the fabrication process of Au covered polymer nanostructure arrays using roll-to-roll ultraviolet nanoimprint lithography (R2R UV-NIL) technique (b) and (c) SERS spectra of R6G from $30 \mathrm{~nm}$ Au coating flexible substrate at different bending angles and bending cycles, respectively. Figure reproduced with permission from ref. ${ }^{114}$, under a Creative Commons Attribution 4.0 International License. 
$40 \mathrm{~mW} / \mathrm{cm}^{2}$ ) nanoimprint lithography (R2R UV-NIL) technique (3) Au coating on polymer nanostructures by ion sputtering. Here, the effect of Au coating thickness $15,30,45,60 \mathrm{~nm}$ on SERS was investigated by varying the sputtering durations of $90,180,270$, and $360 \mathrm{~s}$, respectively. The SERS performance was assessed with probe molecule $\mathrm{R} 6 \mathrm{G}$ and it was noticed $30 \mathrm{~nm}$ Au coating substrate shows the highest Raman signal with $\mathrm{EF}$ $1.21 \times 10^{7}$. Subsequently, the flexible effect on SERS under some mechanical deformations was investigated with different bending angles $\left(10^{\circ}, 45^{\circ}\right.$ and $\left.80^{\circ}\right)$ and bending cycles $(0,100$ and 200). In the SERS signal intensity and peak positions plot, there was also no obvious difference with the corresponding spectra shown in Fig. 10(b) and 10 (c).

Fang et $\mathrm{al}^{115}$. recently reported polymer [polytetrafluoroethylene (PTFE)] based flexible SERS substrates fabricated using versatile femtosecond [290 fs, $1030 \mathrm{~nm}$, $200 \mathrm{kHz}, 1500 \mathrm{~mW}$ ] laser direct writing technique. 3D patterned polymer micro-/nano-structures were obtained and were subsequently coated with $\mathrm{Ag}$ using thermal evaporation technique. These flexible SERS substrates were used to detect R6G at a concentration of $10^{-7}$ $\mathrm{M}$. The advantages of the fs laser processing were its simplicity, high-speed, and possibility of preparing large area substrates, which leads to bulk sample preparation for practical applications. Over the last few years, our research group at the University of Hyderabad, India has successfully fabricated a variety of SERS substrates using fs laser ablation of bulk targets such as $\mathrm{Au}^{116-118}, \mathrm{Si}^{119,120}$, and $\mathrm{Ag}^{121}$, and optimized them by varying the various laser parameters. In future, we aim to prepare low-cost flexible SERS substrates using fs laser pulses for easy sample collection and real-world applications. The nanocolloids and nanostructures obtained with fs laser ablation (in liquids) technique are ubiquitous and versatile. The recent developments in this area of research have proven that these can now be produced in large quantities.

\section{Textile based SERS substrates}

The textile fabrics have also been investigated as an attractive SERS substrate (akin to paper and electrospun fiber substrate) because the fabric is naturally strong, flexible, soft, and a lightweight material. In textiles, various materials are available such as cotton, wool, silk, etc.. Comparable to other flexible substrates, the loading of NPs can be done in two ways, i.e., in-situ synthesis [soaking in different metal salts] and direct deposition of NPs [anisotropic silver nano-prisms and nano-disks to wool fabric has been reported recently ${ }^{122}$. Liu et al ${ }^{123}$. synthesized silk fabrics SERS substrate by soaking in $\mathrm{HAuCl}_{4}$ (0.1-0.6 mM, $50 \mathrm{~mL}$ ) for 30 minutes, followed by heating and cleaning. These Au NPs loaded silk fabrics were used to detect CV, 4-MPy, and PATP. Chen et $\mathrm{al}^{124}$. fabricated Ag-based cotton fabric by soaking in $\mathrm{AgNO}_{3}$ (50-250 mM) followed by reduce-drying $\left(30{ }^{\circ} \mathrm{C}\right.$ for 30 $\mathrm{min}$ ) process. The fabric soaked in $200 \mathrm{mM}$ demonstrated better sensitivity $\left(10^{-12} \mathrm{M}\right)$ with $20 \%$ reproducibility and 57 days stability in the detection of p-Aminothiophenol. Furthermore, these fabric substrates are having other applications UV protection, antibacterial, and self-cleaning ${ }^{125,126}$. Gao et al ${ }^{127}$. reported wash free metallic textile utilization as flexible SERS substrate for the detection of fungicide. They fabricated Ag-coated cotton fabric using magneton sputtering and the SERS performance was optimized with $\mathrm{Ag}$ film thickness as $100 \mathrm{~nm}$ from the series of thickness such as 50,100, 150 and 200 $\mathrm{nm}$ on cotton fabric using MB as a probe molecule. The optimized $100 \mathrm{~nm} \mathrm{Ag-cotton} \mathrm{fabric} \mathrm{substrate} \mathrm{used} \mathrm{to} \mathrm{de-}$ tect $\mathrm{MB}$ at a low concentration of $10^{-12} \mathrm{M}$, for the real time usage they detected thiram on $10 \mathrm{ppb}$. Additionally, they have shown the reusability of these substrates by alternative usage of $\mathrm{MB}$ and $\mathrm{MG}$, this dye droplet was removed by a simple stream of air. Lu et $\mathrm{a}^{128}$. synthesized carbon fiber cloth substrate loaded with 3D Ag nanodendrites by electrochemical deposition. SERS substrate preparation was optimized by studying the effect of deposition voltage (1.1, 1.2, and $1.3 \mathrm{~V})$ and deposition time $(80,120,160,200,240 \mathrm{~s})$, and the optimal SERS substrate was selected by observing nanodendrites morphology and SERS efficiency as under a voltage of $1.3 \mathrm{~V}$ and with deposition time of $160 \mathrm{~s}$, shown in Fig. 11. They reported the detection of $1 \mathrm{pM} \mathrm{CV}$ and simultaneous detection of three other molecules (4-MBA $-5 \mathrm{ppm}$, DDTC $-5 \mathrm{ppm}$, and thiram $-5 \mathrm{ppm}$ ). They presented the real time detection data (SERS spectra) of thiram (5 ppm) and MG (5 ppm), respectively, on superhydrophobic AgNDs/carbon fiber cloth substrate. Further, they also demonstrated the detection of thiram and MG simultaneously in real lake water using superhydrophobic $\mathrm{Ag}$ NDs/carbon fiber cloth substrate. Zhang et al ${ }^{129}$. recently reported the synthesis of non-woven (NW) fabric based SERS substrate and utilized for carbaryl pesticides trace detection on fruits surfaces. NW@polydopamine (PDA) @AgNPs fabrics SERS substrates were fabricated by insitu growth using mussel-inspired PDA molecules. The 
a

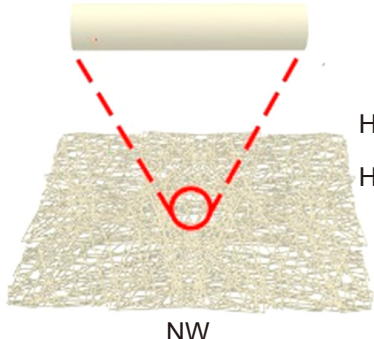

NW

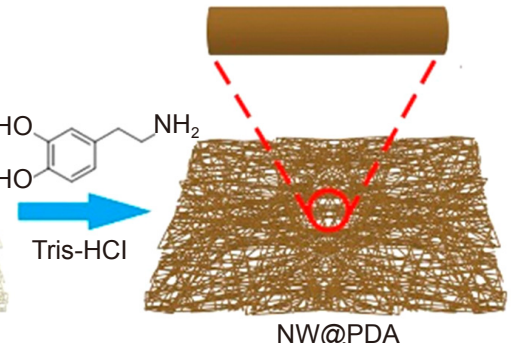

NW@PDA

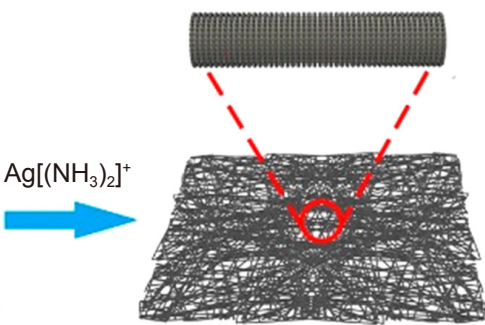

NW@PDA@AgNPs
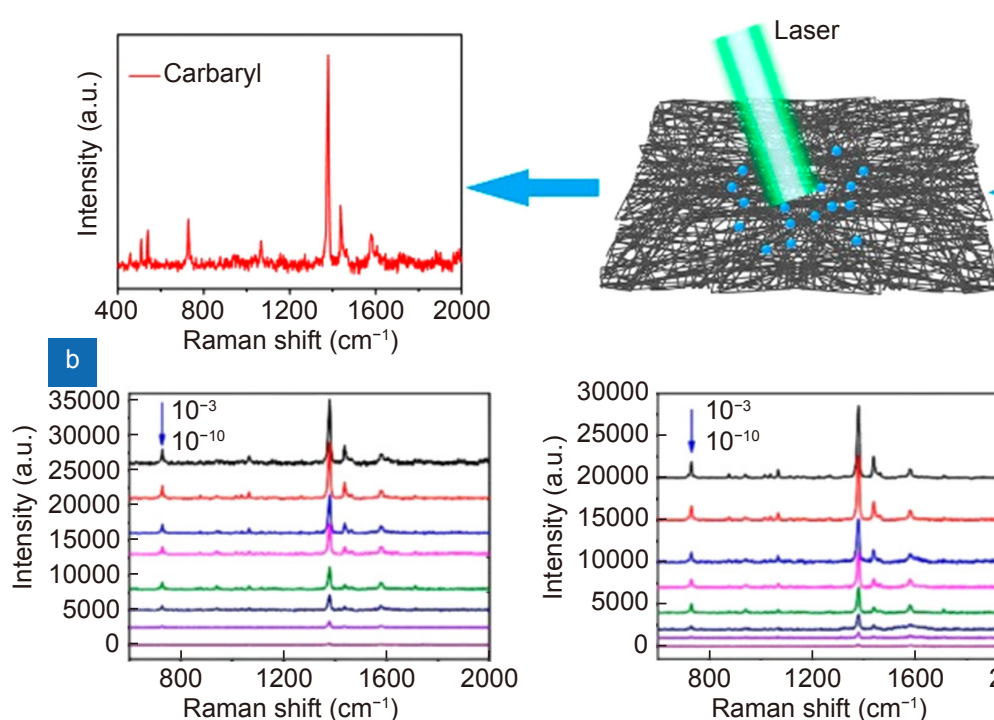

Carbaryl
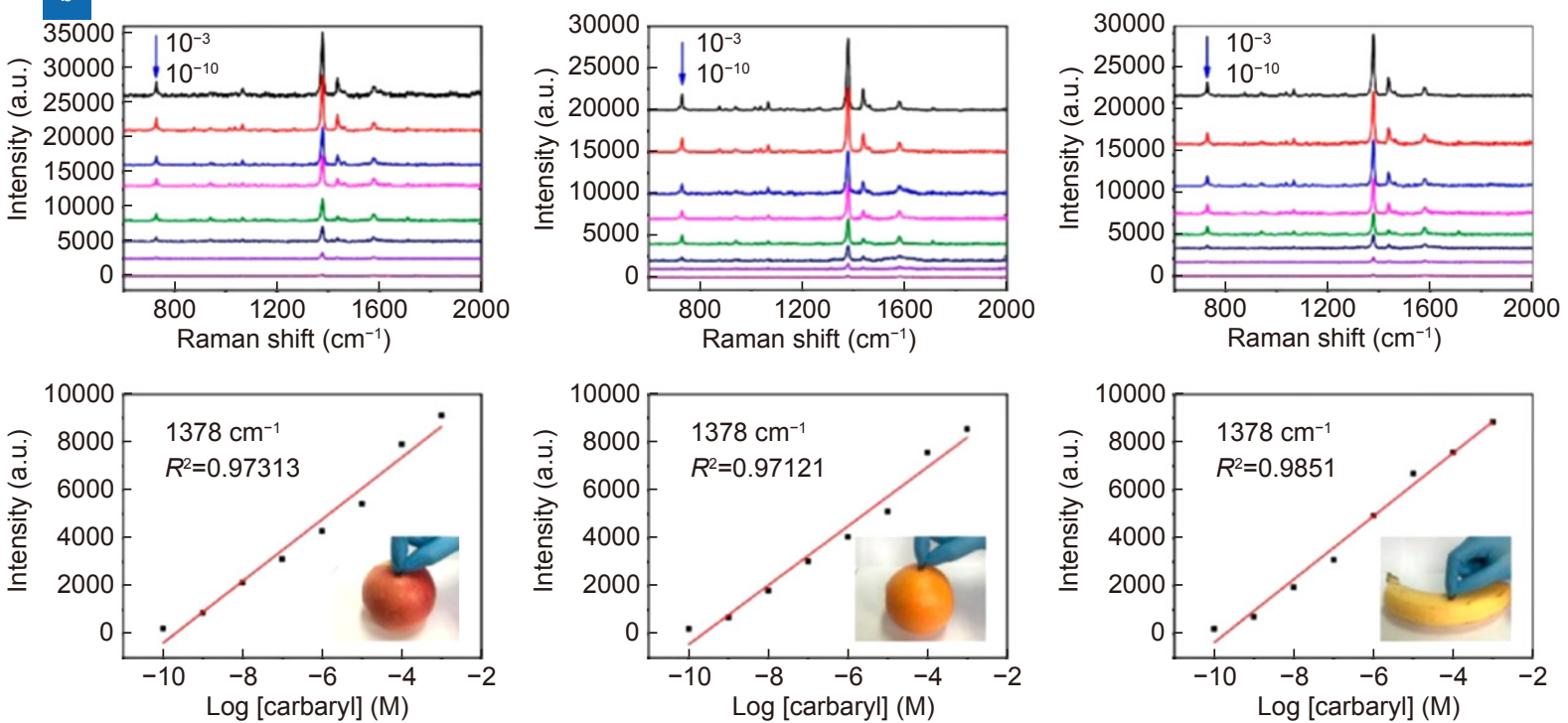

Fig. 11 | (a) Schematic of flexible non-woven fabric based substrate and the (b) SERS spectra of carbyl on apples, oranges, and bananas surfaces. Figure reproduced with permission from ref. ${ }^{129}$, under a Creative Commons Attribution 4.0 International License.

schematic of the fabrication of flexible NW@PDA@Ag NPs substrate and their utilization by simple swabbing method are illustrated in Fig. 11(a). The substrate was optimized by monitoring the immersion time of NW@PDA fabrics in the $\left[\mathrm{Ag}\left(\mathrm{NH}_{3}\right)_{2}\right]^{+}$solution. With increasing the immersion time from 4 hours to 12 hours, the amount of Ag NPs on fabric was increased, and the superior SERS signal was noticed for 12 hours. The optimized flexible NW@PDA@Ag NPs substrates were subsequently utilized to detect the sprayed diluted carbaryl on the surfaces of apples, oranges, and bananas. The collected SERS spectra of carbyl with concentra- tions ranging from $\mathrm{mM}$ to $\mathrm{pM}$ are shown in Fig. 11(b). This is a rapidly growing area of research and has strong potential in the preparation and utilization of flexible SERS substrates for detection of hazardous materials. Different plasmonic nanoparticles (sizes, shapes, preparation methods, concentrations etc.) need to tested and methods optimized with these textiles before we can think of any practical application.

Table 2 summarizes the most important details of recently reported flexible SERS substrates including their preparation methods, materials used in those studies, and the sensitivities achieved. Such data is extremely im- 
Table 2 | Summary of the recent flexible SERS substrates, their preparation methods, materials used, and the sensitivities achieved (2014-2021).

\begin{tabular}{|c|c|c|c|c|c|}
\hline $\begin{array}{c}\text { Flexible substrate } \\
\text { type }\end{array}$ & $\begin{array}{l}\text { Hazardous } \\
\text { material type } \\
\text { studied }\end{array}$ & Method used & SERS active material & Molecules investigated - sensitivity & Ref. \\
\hline \multirow{21}{*}{ Paper/Cellulose } & \multirow{6}{*}{ Explosives } & Inkjet printing & $\begin{array}{l}\text { PABT modified-Ag NPs-A4 } \\
\text { paper }\end{array}$ & TNT- pM & ref. $^{132}$ \\
\hline & & In-situ & $\begin{array}{l}\text { Ag NPs in agarose film } \\
\text { supported on filter paper }\end{array}$ & TNT- $10^{-8} \mathrm{M}$ & ref. $^{78}$ \\
\hline & & Immersion & Ag nano triangles-filter paper & $\begin{array}{l}\text { PA- } 10^{-6} \mathrm{M} \\
\text { p-ATP- } 10^{-8} \mathrm{M}\end{array}$ & ref. $^{88}$ \\
\hline & & Soaking & $\begin{array}{l}\text { Aggregated Ag/Au NPs-filter } \\
\text { paper }\end{array}$ & $\begin{array}{l}\text { PA- } 5 \mu \mathrm{M} \\
\text { DNT- } 1 \mu \mathrm{M} \\
\text { NTO- } 10 \mu \mathrm{M}\end{array}$ & ref. ${ }^{94}$ \\
\hline & & Drop casting & Star-shaped Au NPs & PA- $5 \mu \mathrm{M}$ & ref. $^{133}$ \\
\hline & & Reduction & $\begin{array}{l}\text { Ag Nanostructures- filter paper } \\
\text { Whatman } 42\end{array}$ & $\begin{array}{l}\text { Urea nitrate- } 10^{-6} \mathrm{M} \\
\mathrm{CV}-10^{-8} \mathrm{M}\end{array}$ & ref. ${ }^{134}$ \\
\hline & \multirow[t]{2}{*}{ Drugs } & Inkjet printing & Ag- chromatography paper & $\begin{array}{l}\text { Organophosphate malathion } \\
-413 \mathrm{pg}, \text { Heroin }-9 \mathrm{ng}, \\
\text { Cocaine }-15 \mathrm{ng}\end{array}$ & ref. $^{135}$ \\
\hline & & $\begin{array}{l}\text { Plasma assisted } \\
\text { chemical deposition }\end{array}$ & $\begin{array}{l}\text { Au-Whatman filter paper } \\
\text { grade } 1\end{array}$ & Cocaine- $1 \mathrm{ng} / \mathrm{ml}$ & ref. $^{136}$ \\
\hline & \multirow{3}{*}{ Dyes } & In-situ & $\begin{array}{l}\text { Ag NPs-polydopamine -Filter } \\
\text { paper }\end{array}$ & $\begin{array}{l}\text { R6g- } 10^{-10} \mathrm{M} \\
\text { MG residue on } \\
\text { Fish scales- } 0.04635 \mathrm{pg} / \mathrm{cm}^{2} \text {, } \\
\text { Crab shells- } 0.06952 \mathrm{pg} / \mathrm{cm}^{2} \text { and } \\
\text { Shrimp skins- } 0.09270 \mathrm{pg} / \mathrm{cm}^{2}\end{array}$ & ref. $^{137}$ \\
\hline & & Inkjet-printing & $\begin{array}{l}\mathrm{MoO}_{3-\mathrm{x}} \text { nanosheets on } \\
\text { Chromatographic paper, } \\
\text { printing paper, } \\
\text { filter paper }\end{array}$ & $\begin{array}{l}\text { R6g- } 10^{-7} M \\
C V-10^{-6} M \text { and } M G-10^{-6} M \text { on fish } \\
\text { surface }\end{array}$ & ref. $^{74}$ \\
\hline & & In-situ & Au-filter paper (Advantec \#1) & MG-damped fish-10 ppb & ref. $^{138}$ \\
\hline & \multirow{10}{*}{ Pesticides } & Silver mirror reaction & Ag- filter paper & Thiram- $10^{-7} \mathrm{M}$ & ref. $^{139}$ \\
\hline & & Pen on paper & $\begin{array}{l}\text { Au NPs }(15-120 \mathrm{~nm}) \text {; Au NRs } \\
\text { ( } 50 \mathrm{~nm} \text { long, } 14 \mathrm{~nm} \text { thick); Ag } \\
\text { NPs (50-80 nm) -A4 paper, } \\
\text { Filter paper }\end{array}$ & Thiabendazole $<20 \mathrm{ppb}$ & ref. $^{73}$ \\
\hline & & Airbrush spray method & Ag NPs -glass fibre paper & Enoxacin \& Enrofloxacin- $10^{-5} \mathrm{M}$ & ref. $^{140}$ \\
\hline & & Printing & $\begin{array}{l}\text { Au@Ag } 30 \mathrm{~nm} \text { Au core } \& 7 \mathrm{~nm} \\
\text { Ag shell -filter paper }\end{array}$ & Thiram- $10^{-9} \mathrm{M}$ & ref. $^{141}$ \\
\hline & & Screen printing & Ag NPs/GO- paper & $\begin{array}{l}\text { Thiram } 0.26 \mathrm{ng} \mathrm{cm}^{-2} \\
\text { Thiabendazole } 28 \mathrm{ng} \mathrm{cm}^{-2} \\
\text { Methylparathion } 7.4 \mathrm{ng} \mathrm{cm}^{-2}\end{array}$ & ref. $^{142}$ \\
\hline & & $\begin{array}{l}\text { Immersion followed by } \\
\text { APTMS }\end{array}$ & Ag NPs-PDMS sponge & $\begin{array}{l}\text { Triazophos } 0.79 \mathrm{ng} \\
\text { Methyl Parathion } 1.58 \mathrm{ng}\end{array}$ & ref. $^{143}$ \\
\hline & & $\begin{array}{l}\text { Vacuum-assisted } \\
\text { filtration }\end{array}$ & AuNPs- cellulose nanofiber & $\begin{array}{l}\text { Thiram- } 1 \mathrm{pM} \\
\text { Tricyclazole- } 10 \mathrm{pM}\end{array}$ & ref. $^{144}$ \\
\hline & & In-situ & Au NPs-pseudo-paper & Thiram- $1.1 \mathrm{ng} / \mathrm{cm} 2$ & ref. $^{145}$ \\
\hline & & Laser techniques & Au/Ag film-print paper & $\begin{array}{l}\text { Fungicide mancozeb (Dithane DG) and } \\
\text { insecticide thiamethoxam (Aktara } 25 \\
\text { BG) }\end{array}$ & ref. $^{.146}$ \\
\hline & & $\begin{array}{l}\text { Immerson in } \mathrm{NaCl} \\
\text { solution for } 5 \mathrm{~min}+\text { dip- } \\
\text { coating }\end{array}$ & Ag NPs- filter Paper & $\begin{array}{l}\text { Melamine- } 1 \text { ppm } \\
\text { Thiram- } 1 \text { ppm }\end{array}$ & ref. $^{147}$ \\
\hline
\end{tabular}


Table 2 (Continued)

\begin{tabular}{|c|c|c|c|c|c|}
\hline $\begin{array}{c}\text { Flexible substrate } \\
\text { type }\end{array}$ & $\begin{array}{l}\text { Hazardous } \\
\text { material type } \\
\text { studied }\end{array}$ & Method used & SERS active material & Molecules investigated - sensitivity & Ref. \\
\hline & & Immersion & FP-Au NPs & Methyl parathion- $0.011 \mu \mathrm{g} / \mathrm{cm}^{2}$ & ref. $^{148}$ \\
\hline & & In-situ & Nanocellulose fibers-Ag NPs & $\begin{array}{l}\text { Thiram- } 0.05 \mathrm{ppm} \\
\text { Thiabendazole- } 0.09 \mathrm{ppm} \text {, } \\
\text { MG } 0.0014 \mathrm{ppm} \\
\text { Enrofloxaci- } 0.069 \mathrm{ppm}\end{array}$ & ref. $^{149}$ \\
\hline & & $\begin{array}{l}\text { Silicon } \\
\text { rubber mask and a } \\
\text { vacuum filtration }\end{array}$ & Au NRs -cellulose hydrogels & Thiram- $100 \mathrm{fM}$ & ref. ${ }^{92}$ \\
\hline & & Drop casting & $\begin{array}{l}\text { Quartz paper/Cellulose } \\
\text { nanofiber/ mixture (Ag NPs+Au } \\
\text { NSs) }\end{array}$ & Ferbam on kale leaves $(50 \mu \mathrm{g} / \mathrm{kg})$ & ref. ${ }^{150}$ \\
\hline & & Vacuum filtration & Cellulose nanofibers-Au NPs & Thiram- $10^{-8} \mathrm{M}$ & ref. $^{151}$ \\
\hline & & $\begin{array}{l}\text { Drop casting, inkjet } \\
\text { printing }\end{array}$ & Au NPs-Whatman 44 FP & $\begin{array}{l}\text { Benzenethiol chemical aerosol } \\
\text { Pyridine }\end{array}$ & ref. ${ }^{152}$ \\
\hline & & Vacuum filtration & $\begin{array}{l}\text { Glass-fiber filter paper-Ag NWs } \\
\text { coupled with polymerase chain } \\
\text { reaction (PCR) }\end{array}$ & DNA & ref. $^{153}$ \\
\hline & & $\begin{array}{l}\text { Electrochemical } \\
\text { deposition }\end{array}$ & $\begin{array}{l}\text { Mesoporous Au film@Ag } \\
\text { NWs@cellulose nanofiber paper }\end{array}$ & $\begin{array}{l}\mathrm{R} 6 \mathrm{~g} \text { - } 100 \mathrm{fM} \\
\text { Thiram - } 10 \mathrm{fM} \\
\text { 2-naphthalenethiol-1 ppb }\end{array}$ & ref. ${ }^{154}$ \\
\hline & & Self-assembling & $\begin{array}{l}\text { Cellulose nanofibers - } \\
\text { Ag@DNA/PDA (polydopamine) }\end{array}$ & $\begin{array}{l}\text { Rhodamine } 6 \mathrm{G} \text {. } \\
\text { Thiamethoxamon- } 0.003 \mathrm{mg} / \mathrm{kg} \text {. }\end{array}$ & ref. $^{155}$ \\
\hline \multirow{4}{*}{ Cotton buds } & Antibiotics & In situ reduction & $\begin{array}{l}\text { Ag NPs-cellulose nanocrystals- } \\
\text { Filter paper }\end{array}$ & $\begin{array}{l}\text { Phenylethanolamine } \mathrm{A}-10^{-9} \mathrm{M} \\
\text { Metronidazole- } 10^{-7} \mathrm{M}\end{array}$ & ref. ${ }^{93}$ \\
\hline & Explosives & Self-assembly \& In situ & Ag NPs-cotton swab & 2,4 DNT- 5 ng & ref. $^{156}$ \\
\hline & \multirow{2}{*}{ Pesticides } & $\begin{array}{l}\text { Soaking, freezing, and } \\
\text { drying }\end{array}$ & Ag NPs-chitosan foam & $\begin{array}{l}\text { Triasophols } \\
\text { Methidathion } \\
\text { Isocrabophos }\end{array}$ & ref. $^{157}$ \\
\hline & & Dipping \& drying & Ag NPs-cotton swab with $\mathrm{NaCl}$ & $\begin{array}{l}\text { Thiabendazole (TBZ), } \\
\text { thiram, } \\
\text { TBZ + thiram }\end{array}$ & ref. $^{158}$ \\
\hline \multirow{5}{*}{ Nanofiber mat } & Explosives & In situ & Ag NPs -polyurethane sponge & $\begin{array}{l}\text { Perchlorates- } 0.13 \mathrm{ng} \\
\text { CChlorates- } 0.13 \mathrm{ng} \\
\text { Nitrates- } 0.11 \mathrm{ng}\end{array}$ & ref. ${ }^{159}$ \\
\hline & Pesticides & Electrospinning & Au coated PVA nanofiber & $\begin{array}{l}\text { Deltamethrin- } 0.33 \mathrm{mg} / \mathrm{kg} \\
\text { Quinalphos- } 0.28 \mathrm{mg} / \mathrm{kg} \\
\text { Thiacloprid- } 0.26 \mathrm{mg} / \mathrm{kg}\end{array}$ & ref. ${ }^{104}$ \\
\hline & CWA simulants & Electrospinning & Au NPs -PVA nanofiber & Methyl salicylate & ref. ${ }^{160}$ \\
\hline & \multirow[b]{2}{*}{ Dyes } & Electrospinning & Ag NPs-PVA nanofiber & R6G-10-5 M & ref. $^{161}$ \\
\hline & & $\begin{array}{l}\text { Electrospinning and in- } \\
\text { situ }\end{array}$ & $\begin{array}{l}\text { Ag NPs-Polyimide (PI) } \\
\text { nanofabric }\end{array}$ & $\begin{array}{l}\text { p-Aminothiophenol (p-ATP)- } 10^{-14} \\
\mathrm{~mol} / \mathrm{L})\end{array}$ & ref. $^{162}$ \\
\hline \multirow{5}{*}{ Fabric } & \multirow{5}{*}{ Pesticides } & Self-assembly/in-situ & Ag NPs- non woven fabric & $\begin{array}{l}\text { Isocarbophos } \\
\text { Sumicidin } \\
\text { Phosgene }\end{array}$ & ref. $^{.163}$ \\
\hline & & Dip coating & $\begin{array}{l}\text { Triangular Ag nanoplates- } \\
\text { Cotton fabric }\end{array}$ & Carbaryl- $10^{-5} \mathrm{M}$ & ref. $^{164}$ \\
\hline & & In situ & $\begin{array}{l}\text { Polydopamine mediated Ag-Au } \\
\text { NPs - cotton fabric }\end{array}$ & Carbaryl- $10^{-6} \mathrm{M}$ & ref. $^{165}$ \\
\hline & & Magneton sputtering & Ag NPs-cotton fabric & Thiram - 1 ppm & ref. $^{127}$ \\
\hline & & Magnetron sputtering & Ag-polyester fabric & R6G on cucumber, MG and Thiram & ref. ${ }^{166}$ \\
\hline
\end{tabular}


Table 2 (Continued)

\begin{tabular}{|c|c|c|c|c|c|}
\hline $\begin{array}{l}\text { Flexible substrate } \\
\text { type }\end{array}$ & $\begin{array}{l}\text { Hazardous } \\
\text { material type } \\
\text { studied }\end{array}$ & Method used & SERS active material & Molecules investigated - sensitivity & Ref. \\
\hline & & $\begin{array}{l}\text { Photochemical } \\
\text { deposition }(254 \mathrm{~nm})\end{array}$ & $\begin{array}{l}\mathrm{Ag} \mathrm{NPs} \text { on } \mathrm{TiO}_{2} \text { coated } \\
\text { polyester fiber membranes }\end{array}$ & $\begin{array}{l}\text { Sodium saccharin in soft drinks- } 0.3 \\
\mathrm{mg} / \mathrm{L}, \text { (cola and sprite) }\end{array}$ & ref. $^{167}$ \\
\hline & & In-situ growth & Ag NPs-Cotton fabrics & PATP- $10^{-8} \mathrm{M}$ & ref. $^{168}$ \\
\hline & & Vacuum evaporation & Ag coated $(10 \mathrm{~nm})$ nylon fabrics & $\begin{array}{l}\text { PATP- } 10^{-9} \mathrm{M} \\
\text { Thiram on cucumber surface- } 10^{-7} \mathrm{M}\end{array}$ & ref. $^{169}$ \\
\hline \multirow{17}{*}{ Polymers } & \multirow{6}{*}{ Explosives } & $\begin{array}{l}\text { Vacuum thermal } \\
\text { evaporation and high- } \\
\text { temperature annealing } \\
\text { Oriented stacking and in- } \\
\text { situ }\end{array}$ & $\begin{array}{l}\text { Ag NPs-carbon fiber cloth } \\
\text { Ag and Au-Ag nanoplates- PET }\end{array}$ & $\begin{array}{l}\text { R6g- } 10^{-14} \mathrm{~mol} \cdot \mathrm{L}^{-1} \\
\text { TNT- } 10 \mathrm{nM} \\
\text { RDX- } 10 \mathrm{nM}\end{array}$ & ref. $^{171}$ \\
\hline & & Self-assembling & $\begin{array}{l}\text { Au triangular nanoprisms on } \\
\text { adhesive film (Scotch magic- } \\
\text { tape) }\end{array}$ & $\begin{array}{l}\text { TNT- } 900 \text { ppq } \\
\text { RDX- } 50 \text { ppq and } \\
\text { PETN- } 50 \text { ppq }\end{array}$ & ref. $^{58}$ \\
\hline & & $\begin{array}{l}\text { Incubated overnight } \\
\text { followed by thorough } \\
\text { rinsing drying }\end{array}$ & $\begin{array}{l}\text { Au NPs,Au NRs and Au NCs on } \\
\text { elastomeric film (PDMS) }\end{array}$ & TNT vapor & ref. $^{172}$ \\
\hline & & Gravure printing & Ag NPs-PET & DNT vapor & ref. $^{173}$ \\
\hline & & $\begin{array}{l}\text { Sol-gel method and } \\
\text { magnetron sputtering }\end{array}$ & Ag NPs-Porous silica aerogels & NTO- $7.94 \times 10^{-10} \mathrm{M}$ & ref. ${ }^{174}$ \\
\hline & & $\begin{array}{l}\text { UV lithography and } \\
\text { Au deposition }\end{array}$ & $\begin{array}{l}\text { Ag NPs-Au coated - } \\
\text { nanowrinkled zigzag } \\
\text { micropattern on PDMS layer }\end{array}$ & $\begin{array}{l}\text { TNT- } 10^{-13} \mathrm{~mol} \cdot \mathrm{L}^{-1} \\
\text { TNT residue }\left(10^{-9} \mathrm{~mol} \cdot \mathrm{L}^{-1}\right) \text { on cloth bag }\end{array}$ & ref. $^{175}$ \\
\hline & \multirow{5}{*}{ Dyes } & $\begin{array}{l}\text { Electron-beam } \\
\text { evaporation-uniaxial } \\
\text { stretching }\end{array}$ & $\begin{array}{l}\text { Stretched } \mathrm{Ag} \text { coated poly }(\varepsilon- \\
\text { caprolactone }) \text { film }\end{array}$ & MG-green mussel surface- $0.1 \times 10^{-6} \mathrm{M}$ & ref. ${ }^{176}$ \\
\hline & & Pyramid Si template & $\begin{array}{l}\mathrm{MoS}_{2} / \mathrm{AgNPs}_{\text {inverted pyramidal }} \\
\text { PMMA }\end{array}$ & R6G+MG & ref. $^{177}$ \\
\hline & & Pyramid Si template & GO/Ag NPs/ pyramidal PMMA & MG on shrimp & ref. $^{178}$ \\
\hline & & $\begin{array}{l}\text { Ar plasma etching and } \\
\text { Au evaporation }\end{array}$ & Worm-like Au NSs - PET film & R6G-10-9 M & ref. ${ }^{179}$ \\
\hline & & $\begin{array}{l}\text { Self-assembly and in situ } \\
\text { chemical reduction }\end{array}$ & $\begin{array}{l}\text { Raspberry-like polyamide@Ag } \\
\text { hybrid nanoarray film }\end{array}$ & $\begin{array}{l}\text { R6g- } 10^{-14} \mathrm{M} \\
\text { Adenosine- } 10^{-9} \mathrm{M}\end{array}$ & ref. $^{180}$ \\
\hline & \multirow{6}{*}{ Pesticides } & Drop-dry method & Au NPs $(25 \mathrm{~nm})$ - adhesive tape & $\begin{array}{l}\text { Parathion-methyl- } 2.60 \mathrm{ng} / \mathrm{cm}^{2} \\
\text { Thiram } 0.24 \mathrm{ng} / \mathrm{cm}^{2} \\
\text { Chlorpyrifos } 3.51 \mathrm{ng} / \mathrm{cm}^{2} \\
\text { on apples, oranges, cucumbers, and } \\
\text { green vegetables surfaces }\end{array}$ & ref. $^{181}$ \\
\hline & & $\begin{array}{l}\text { Spin coating and manual } \\
\text { peeling }\end{array}$ & AgNP@AgNW network-PDMS & $\begin{array}{l}\text { Thiram }(0.1 \mu \mathrm{M}) \text { on a leaf surface and } \\
\text { MG }(0.1 \mu \mathrm{M}) \text { on a living fish scale }\end{array}$ & ref. $^{182}$ \\
\hline & & $\begin{array}{l}\text { Paste and peeling of } \\
\text { self-assembled NPs from } \\
\mathrm{Si}\end{array}$ & $\begin{array}{l}\text { Adhesive acrylic polymer tape } \\
\text { and polyethene terephthalate } \\
\text { (PET) film (T/Au@Ag/PET) }\end{array}$ & $\begin{array}{l}\text { Thiram on apple, tomato, and } \\
\text { cucumber peels }\left(5 \mathrm{ng} / \mathrm{cm}^{2}\right)\end{array}$ & ref. $^{.13}$ \\
\hline & & Seed mediated & Gold nanobush+PDMS & $\begin{array}{l}\text { Thiabendazole (TBZ) on cherry }-0.64 \\
\mathrm{ng} / \mathrm{ml} \\
\text { Carbaryl } \\
\text { TBZ+Carbaryl }\end{array}$ & ref. ${ }^{183}$ \\
\hline & & $\begin{array}{l}\text { Femtosecond laser } \\
\text { induced plasma assisted } \\
\text { ablation }\end{array}$ & $\begin{array}{l}\text { Ag NPs and Au NPs FEP } \\
\text { (fluorinated } \\
\text { ethylene propylene) }\end{array}$ & Thiram on apple- $7.96 \mathrm{ng} / \mathrm{cm}^{2}$ & ref. $^{184}$ \\
\hline & & Drop casting & $\begin{array}{l}\text { Ag NS with spikes-adhesive } \\
\text { tape }\end{array}$ & $\begin{array}{l}\text { Phosmet \& carbaryl on apple-surface } \\
10^{-7} \mathrm{M}\end{array}$ & ref. ${ }^{.85}$ \\
\hline
\end{tabular}


portant since the developments are occurring at a rapid pace and it is imperative to identify the strengths and weakness of each of these methodologies to come up with a viable and practical technique for making robust flexible SERS substrates. These flexible SERS substrates find niche applications in the detection of various hazardous materials in Defence, food, and environmental safety issues. Sensitivity estimations are reported in various parameters such as Molar (M), parts per billion (ppb), nanogram (ng), ng/ $\mathrm{cm}^{2}$ and $\mathrm{mg} / \mathrm{kg}$. For example, in case of Thiram molecule (molecular weight of 240.44) $10 \mathrm{ppb}$ is $\sim 0.42 \mathrm{nM}$ which is equivalent to $\sim 1 \mathrm{pg}$ in $10 \mu \mathrm{L}$; $1 \mathrm{ppb}=1 \mu \mathrm{g} / \mathrm{kg} ; 1 \mathrm{ppm}=1000 \mathrm{ppb}$. Table 3 represents a summary of the commercially available SERS substrates (which is not exhaustive) and it is evident that each one of them have varied properties including the sensitivity, stability, and cost. Liu et al ${ }^{130}$. provided a comprehensive evaluation of six commercial substrates [Enspectrc-1 (Silicon based), Q-SERS ${ }^{\mathrm{TM}}-1$ (Silicon based), Ocean optics-3 (paper based Ag, Au; glass based $\mathrm{Ag} / \mathrm{Au}$ ) and Hamamatsu substrate-1 (Au NS on polypropylene)] including their sensitivity and reproducibility studies using the molecules of MB, BPE, 4-MBA. The SERS spectra recorded with XploRA-Plus Raman micro-spectrometer at 532 and $785 \mathrm{~nm}$ excitation wavelengths. From the results the authors observed optimized signals in the case of Enspectrc SERS substrate for all the three molecules at $532 \mathrm{~nm}$; Q-SERS ${ }^{\mathrm{TM}}$ substrate for $4-\mathrm{MBA}$ and BPE at $785 \mathrm{~nm}$; Hamamatsu substrate for MB with 785 $\mathrm{nm}$ excitation. Hakonen et al ${ }^{131}$. have reported the SERSbased detection of forensic substances (Cyclosarin, RDX, Amphetamine and PA) using commercially available substrates and handheld Raman spectrometers. The same could be extended to flexible substrates provided they are efficient (providing high enhancements) for field applications. Further detailed research is required in this direction.

\section{Conclusions and outlook}

In recent years the development and applications of flexible SERS substrate has received incredible attention towards the detection of hazardous materials. In this review, we summarized the most recent research (focusing particularly on the last 3-4 years of research) on flexible based SERS substrates, including paper/cellulose, polymer nanofibers, 3D sponges, fabrics, etc., and their potential on-site detection of explosives, pesticides, chemical warfare agents, drugs for homeland security, food safety, and medical fields. There is a tremendous scope for the flexible SERS substrates in the above-mentioned fields and many others not listed here. Particularly in the field of explosive trace detection, these substrates will be

Table 3 | A summary of the commercially available SERS substrates, their costs, sensitivities and their stability (non-exhaustive).

\begin{tabular}{|c|c|c|c|c|c|c|}
\hline S. No. & Company & SERS substrate & Sensitivity & Stability & Cost & Ref \\
\hline 1 & Stellarnet & Cellulose with Au NPs & $\sim 10^{6}$ & 3 months & $\$ 199$ (pack of 30) & ref. 186 \\
\hline 2 & Horiba France SAS & $\begin{array}{l}\text { Glass coated with Au nanorods } \\
\text { processed by dynamic oblique } \\
\text { vacuum evaporation }\end{array}$ & - & - & - & ref. ${ }^{187}$ \\
\hline 3 & SERSitive & $\begin{array}{l}\text { Electrodeposition of silver and gold } \\
\text { nanoparticles on an ITO glass } \\
\text { surface }\end{array}$ & $\sim 10^{5}-10^{6}$ & 4 months & $\begin{array}{c}5 \text { pcs Ag- } € 115 \\
5 \text { pcs Ag-Au- } € 138\end{array}$ & ref. ${ }^{188}$ \\
\hline 4 & EnSpectr Inc. & $\begin{array}{l}\text { Si/Glass passivated with a thin } \\
\text { transparent dielectic layer. }\end{array}$ & $\sim 10^{6}$ & $\begin{array}{l}\text { Stable when } \\
\text { unpacked }\end{array}$ & - & ref. ${ }^{189}$ \\
\hline 5 & Silmeco & $\begin{array}{l}\text { Nanostructured Si deposited with } \\
\text { Gold }(\mathrm{Au}) \text {, Silver }(\mathrm{Ag})\end{array}$ & - & - & 5 units $€ 350$ & ref. ${ }^{190}$ \\
\hline 6 & Hamamatsu & Au NS on polypropylene & - & $\begin{array}{c}3 \text { months } \\
\text { when unpacked }\end{array}$ & - & ref. 191 \\
\hline 7 & Integrated Optics & $\mathrm{Ag} / \mathrm{Au}$ coating on silicate glass. & - & 2 months & $\begin{array}{l}\text { Ag- } € 15 \\
\text { Au- } € 18\end{array}$ & ref. 192 \\
\hline 8 & $\begin{array}{c}\text { Mesophotonics. Ltd. } \\
\text { Klarite }\end{array}$ & $\mathrm{Si}$ & - & - & $\begin{array}{l}100 \text { USD for single } \\
2 \mathrm{~mm} \times 2 \mathrm{~mm} \\
\text { sample. }\end{array}$ & ref. 193 \\
\hline 9 & Q SERS TM & Au NSs on $\mathrm{Si}(5 \mathrm{~mm} \times 5 \mathrm{~mm})$ & $\mathrm{ppb}$ to $\mathrm{ppm}$ & $\begin{array}{c}6 \text { months (package) } \\
2 \text { weeks (package } \\
\text { opened) }\end{array}$ & 2 units $\$ 50$ USD & ref. ${ }^{194}$ \\
\hline 10 & Metrohm & Ag, Au based Filter paper & - & - & - & ref. 195 \\
\hline
\end{tabular}


highly beneficial. For example, explosives trace swiping/swabbing from luggage surfaces, clothing, vehicle surfaces, post-blast sites will be easier with such flexible substrates. These explosive molecules are sticky and leave behind small traces while handling and transporting them (on various surfaces). Such traces can be easily detected using efficient SERS substrates. Combined with a portable or handheld Raman spectrometers enriched with database/libraries of all explosive molecules, it presents a very attractive methodology for identification and prevention of terrorist activities. Similarly, testing food materials with these substrates enables prevention of easy adulteration (e.g., drinking water, milk, edible oils). Although there are several issues (e.g., further improvements in the sensitivity, long-term stability, reducing the costs) that need to be addressed for each of these methods. But there is also a huge scope for research in these areas, and we firmly believe the developments in these research areas will lead to practical devices.

Additionally, the recent developments in the understanding of SERS substrates (both plasmonic and nonplasmonic) and their potential have increased by leaps and bounds, the proof of which is evident from the number of review articles published in this area ${ }^{196-198}$.

Different real-world applications that can be envisaged with these SERS substrates include

(a) Biomedical applications, bioimaging and biosensing ${ }^{54,199,200}$;

(b) Inspection in food quality and safety ${ }^{201}$;

(c) Biochemical and medical analysis ${ }^{198}$;

(d) Virus detection (including COVID-19)202,203;

(e) Plant disease diagnostics ${ }^{204}$;

(f) Forensics ${ }^{205}$.

Since there are numerous methods by which SERS substrates can be fabricated ${ }^{206,207}$, it is imperative that a huge number of efforts are out to identify the niche application(s) for each one of them. For example, one may need to compromise on the cost if we need detection of femtomolar concentration of desired analyte molecule. Similarly, sensitivity is not an issue in some specific cases and cost needs to be considered. There are also tremendous advances in the preparation of nanofibrous mats ${ }^{208,209}$ and combination of potential SERS NPs/NSs incorporation in these mats can lead to development of agile, lowcost, and versatile SERS substrates for various applications.

\section{References}

1. Bharati MSS. Rigid, flexible sers substrates fabricated using femtosecond laser pulses for explosives detection (Ph.D. Thesis, Submitted to University of Hyderabad, Hyderabad, India, 2020).

2. Zamora-Sequeira $R$, Starbird-Pérez $R$, Rojas-Carillo $O$, Vargas-Villalobos $\mathrm{S}$. What are the main sensor methods for quantifying pesticides in agricultural activities? a review. Molecules 24, 2659 (2019).

3. National Research Council. Acute Exposure Guideline Levels for Selected Airborne Chemicals: Volume 3 (The National Academies Press, Washington, 2003).

4. Bartelt-Hunt SL, Knappe DRU, Barlaz MA. A review of chemical warfare agent simulants for the study of environmental behavior. Crit Rev Environ Sci Technol 38, 112-136 (2008).

5. Kumar V. Chromo-fluorogenic sensors for chemical warfare agents in real-time analysis: journey towards accurate detection and differentiation. Chem Commun 57, 3430-3444 (2021).

6. Jindal MK, Mainuddin M, Veerabuthiran S, Razdan AK. Laser based systems for standoff detection of CWA: a short review. IEEE Sens J 21, 4085-4096 (2021).

7. Wallin S, Pettersson A, Östmark H, Hobro A. Laser-based standoff detection of explosives: a critical review. Anal Bioanal Chem 395, 259-274 (2009).

8. Mokalled L, Al-Husseini M, Kabalan KY, El-Hajj A. Sensor review for trace detection of explosives. Int J Sci Eng Res 5, 337-350 (2014).

9. Singh S. Sensors - an effective approach for the detection of explosives. J Hazard Mater 144, 15-28 (2007).

10. Ruan $S$, Chen $Y Z$, Zhang $P$, Pan $X Z$, Fang $C$ et al. Online remote monitoring of explosives by optical fibres. RSC Adv $\mathbf{6}$, 103324-103327 (2016).

11. Konstantynovski K, Njio G, Börner F, Lepcha A, Fischer T et al. Bulk detection of explosives and development of customized metal oxide semiconductor gas sensors for the identification of energetic materials. Sens Actuators B: Chem 258, 1252-1266 (2018).

12. Wen $P$, Amin M, Herzog WD, Kunz RR. Key challenges and prospects for optical standoff trace detection of explosives. TrAC Trends Anal Chem 100, 136-144 (2018).

13. Davies AG, Burnett AD, Fan WH, Linfield EH, Cunningham JE. Terahertz spectroscopy of explosives and drugs. Mater Today 11, 18-26 (2008).

14. Yinon J. Counterterrorist Detection Techniques of Explosives (Elsevier, Amsterdam, 2007).

15. Moore DS, Scharff RJ. Portable Raman explosives detection. Anal Bioanal Chem 393, 1571-1578 (2009).

16. Christesen SD, Guicheteau JA, Curtiss JM, Fountain AW. Handheld dual-wavelength Raman instrument for the detection of chemical agents and explosives. Opt Eng 55, 074103 (2016).

17. Vandenabeele P. Practical Raman Spectroscopy: An Introduction (John Wiley \& Sons, Chichester, 2013); http://doi.org/10.1002/9781119961284.

18. Mosier-Boss PA. Review of SERS substrates for chemical sensing. Nanomaterials 7, 142 (2017).

19. Sun J, Gong L, Wang WJ, Gong ZJ, Wang DM et al. Surface enhanced Raman spectroscopy for on - site analysis: a review of recent developments. Luminescence 35, 808-820 
(2020).

20. Muehlethaler C, Leona M, Lombardi JR. Review of surface enhanced Raman scattering applications in forensic science. Anal Chem 88, 152-169 (2016).

21. Gares KL, Hufziger KT, Bykov SV, Asher SA. Review of explosive detection methodologies and the emergence of standoff deep UV resonance Raman. J Raman Spectros 47, 124-141 (2016).

22. Zhou HB, Zhang ZP, Jiang CL, Guan GJ, Zhang K et al. Trinitrotoluene explosive lights up ultrahigh Raman scattering of nonresonant molecule on a top-closed silver nanotube array. Anal Chem 83, 6913-6917 (2011).

23. Hakonen A, Rindzevicius T, Schmidt MS, Andersson PO, Juhlin $L$ et al. Detection of nerve gases using surface-enhanced Raman scattering substrates with high droplet adhesion. Nanoscale 8, 1305-1308 (2016).

24. Fleischmann M, Hendra PJ, McQuillan AJ. Raman spectra of pyridine adsorbed at a silver electrode. Chem Phys Lett 26, 163-166 (1974).

25. Jeanmaire DL, Van Duyne RP. Surface Raman spectroelectrochemistry: part I. Heterocyclic, aromatic, and aliphatic amines adsorbed on the anodized silver electrode. J Electroanal Chem Interfacial Electrochem 84, 1-20 (1977).

26. Albrecht MG, Creighton JA. Anomalously intense Raman spectra of pyridine at a silver electrode. J Am Chem Soc 99, 5215-5217 (1977).

27. Moskovits M. Surface roughness and the enhanced intensity of Raman scattering by molecules adsorbed on metals. J Chem Phys 69, 4159-4161 (1978).

28. Rajesh Y, Bharati MSS, Rao SV, Krishna MG. ZnO nanowire arrays decorated with titanium nitride nanoparticles as surfaceenhanced Raman scattering substrates. App/ Phys A 127, 270 (2021).

29. Lan LL, Gao YM, Fan XC, Li MZ, Hao Q et al. The origin of ultrasensitive SERS sensing beyond plasmonics. Front Phys 16, 43300 (2021).

30. Zhen Y, Xu KC, Jiang SZ, Luo D, Chen R et al. Recent progress on two-dimensional layered materials for surface enhanced Raman spectroscopy and their applications. Mater Today Phys 18, 100378 (2021).

31. Basu N, Bharathi MSS, Sharma M, Yadav K, Parmar AS et al. Large area few-layer hexagonal boron nitride as a Raman enhancement material. Nanomaterials 11, 622 (2021).

32. Ge MH, Pan L, Zhou GL, Chen SY, Han W et al. General surface enhanced Raman spectroscopy method for actively capturing target molecules in small gaps. J Am Chem Soc 143, 7769-7776 (2021).

33. Le Ru EC, Etchegoin PG. Quantifying SERS enhancements. MRS Bull 38, 631-640 (2013).

34. Fan MK, Andrade GFS, Brolo AG. A review on the fabrication of substrates for surface enhanced Raman spectroscopy and their applications in analytical chemistry. Anal Chim Acta 693, 7-25 (2011).

35. Mahadeva SK, Walus K, Stoeber B. Paper as a platform for sensing applications and other devices: a review. ACS Appl Mater Interfaces 7, 8345-8362 (2015).

36. Restaino SM, White IM. A critical review of flexible and porous SERS sensors for analytical chemistry at the point-of-sample. Anal Chim Acta 1060, 17-29 (2019)

37. Senthamizhan A, Balusamy B, Uyar T. Glucose sensors based on electrospun nanofibers: a review. Anal Bioanal Chem 408, 1285-1306 (2016).

38. Hakonen A, Andersson PO, Schmidt MS, Rindzevicius T, Käll M. Explosive and chemical threat detection by surface-enhanced Raman scattering: a review. Anal Chim Acta 893, 1-13 (2015).

39. Ogundare SA, van Zyl WE. A review of cellulose-based substrates for SERS: fundamentals, design principles, applications. Cellulose 26, 6489-6528 (2019).

40. Maddipatla D, Narakathu BB, Atashbar M. Recent progress in manufacturing techniques of printed and flexible sensors: a review. Biosensors 10, 199 (2020).

41. Peng XY, Li D, Li YT, Xing HB, Deng W. Plasmonic tunable Ag-coated gold nanorod arrays as reusable SERS substrates for multiplexed antibiotics detection. J Mater Chem B 9, 1123-1130 (2021).

42. Xu KC, Yan HP, Tan CF, Lu YY, Li Y et al. Hedgehog inspired $\mathrm{CuO}$ nanowires $/ \mathrm{Cu}_{2} \mathrm{O}$ composites for broadband visible light - driven recyclable surface enhanced Raman scattering. Adv Opt Mater 6, 1701167 (2018).

43. Zhang DR, Pu HB, Huang LJ, Sun DW. Advances in flexible surface-enhanced Raman scattering (SERS) substrates for nondestructive food detection: fundamentals and recent applications. Trends Food Sci Technol 109, 690-701 (2021).

44. Klapec DJ, Czarnopys G, Pannuto J. Interpol review of detection and characterization of explosives and explosives residues 2016-2019. Forensic Sci Int: Synergy 2, 670-700 (2020).

45. Li ZY, Huang X, Lu G. Recent developments of flexible and transparent SERS substrates. J Mater Chem C 8, 3956-3969 (2020).

46. Forbes TP, Krauss ST, Gillen G. Trace detection and chemical analysis of homemade fuel-oxidizer mixture explosives: emerging challenges and perspectives. TrAC Trends Anal Chem 131, 116023 (2020).

47. Wu JJ, Zhang L, Huang F, Ji XX, Dai HQ et al. Surface enhanced Raman scattering substrate for the detection of explosives: construction strategy and dimensional effect. J Hazard Mater 387, 121714 (2020).

48. Shvalya V, Filipič G, Zavašnik J, Abdulhalim I, Cvelbar U. Surface-enhanced Raman spectroscopy for chemical and biological sensing using nanoplasmonics: the relevance of interparticle spacing and surface morphology. Appl Phys Rev 7, 031307 (2020).

49. To KC, Ben-Jaber S, Parkin IP. Recent developments in the field of explosive trace detection. ACS Nano 14, 10804-10833 (2020).

50. Pérez-Jiménez Al, Lyu DY, Lu ZX, Liu GK, Ren B. Surface-enhanced Raman spectroscopy: benefits, trade-offs and future developments. Chem Sci 11, 4563-4577 (2020).

51. Huang CC, Cheng CY, Lai YS. Paper-based flexible surface enhanced Raman scattering platforms and their applications to food safety. Trends Food Sci Technol 100, 349-358 (2020).

52. Chen MP, Liu D, Du XY, Lo KH, Wang SP et al. 2D materials: excellent substrates for surface-enhanced Raman scattering (SERS) in chemical sensing and biosensing. TrAC Trends Anal Chem 130, 115983 (2020).

53. Xue JJ, Wu T, Dai YQ, Xia YN. Electrospinning and electrospun nanofibers: methods, materials, and applications. Chem Rev 119, 5298-5415 (2019). 
54. Pilot R, Signorini R, Durante C, Orian L, Bhamidipati M et al. A review on surface-enhanced Raman scattering. Biosensors $\mathbf{9}$, 57 (2019).

55. Lee HK, Lee YH, Koh CSL, Phan-Quang GC, Han XM et al. Designing surface-enhanced Raman scattering (SERS) platforms beyond hotspot engineering: emerging opportunities in analyte manipulations and hybrid materials. Chem Soc Rev 48, 731-756 (2019).

56. Xu KC, Zhou R, Takei K, Hong MH. Toward flexible surfaceenhanced Raman scattering (SERS) sensors for point-of-care diagnostics. Adv Sci 6, 1900925 (2019).

57. Zhang S, Jia ZX, Liu TJ, Wei G, Su ZQ. Electrospinning nanoparticles-based materials interfaces for sensor applications. Sensors 19, 3977 (2019).

58. Liyanage T, Rael A, Shaffer S, Zaidi S, Goodpaster JV et al. Fabrication of a self-assembled and flexible SERS nanosensor for explosive detection at parts-per-quadrillion levels from fingerprints. Analyst 143, 2012-2022 (2018).

59. Xu KC, Zhang CT, Lu TH, Wang PQ, Zhou R et al. Hybrid metal-insulator-metal structures on Si nanowires array for surface enhanced Raman scattering. Opto-Electron Eng 44, 185-191 (2017).

60. Fierro-Mercado PM, Hernández-Rivera SP. Highly sensitive filter paper substrate for SERS trace explosives detection. Int $J$ Spectrosc 2012, 716527 (2012).

61. Cui H, Li SY, Deng SZ, Chen HJ, Wang CX. Flexible, transparent, and free-standing silicon nanowire SERS platform for in situ food inspection. ACS Sens 2, 386-393 (2017).

62. Jiang JL, Zou SM, Ma LW, Wang SF, Liao JS et al. Surfaceenhanced Raman scattering detection of pesticide residues using transparent adhesive tapes and coated silver nanorods. ACS Appl Mater Interfaces 10, 9129-9135 (2018).

63. Lee M, Oh K, Choi HK, Lee SG, Youn HJ et al. Subnanomolar sensitivity of filter paper-based SERS sensor for pesticide detection by hydrophobicity change of paper surface. ACS Sens 3, 151-159 (2018).

64. Wang KQ, Sun DW, Pu HB, Wei QY, Huang LJ. Stable, flexible, and high-performance SERS chip enabled by a ternary film-packaged plasmonic nanoparticle array. ACS Appl Mater Interfaces 11, 29177-29186 (2019).

65. Lin Y, Gritsenko D, Liu Q, Lu XN, Xu J. Recent advancements in functionalized paper-based electronics. ACS Appl Mater Interfaces 8, 20501-20515 (2016).

66. Kumar A, Santhanam V. Paper swab based SERS detection of non-permitted colourants from dals and vegetables using a portable spectrometer. Anal Chim Acta 1090, 106-113 (2019).

67. Liu Q, Wang JH, Wang BK, Li Z, Huang H et al. Paper-based plasmonic platform for sensitive, noninvasive, and rapid cancer screening. Biosens Bioelectron 54, 128-134 (2014).

68. Kim EJ, Kim H, Park E, Kim T, Chung DR et al. Paper-based multiplex surface-enhanced Raman scattering detection using polymerase chain reaction probe codification. Anal Chem $\mathbf{9 3}$, 3677-3685 (2021).

69. Park $\mathrm{M}$, Jung $\mathrm{H}$, Jeong $\mathrm{Y}$, Jeong $\mathrm{KH}$. Plasmonic schirmer strip for human tear-based gouty arthritis diagnosis using surfaceenhanced Raman scattering. ACS Nano 11, 438-443 (2017).

70. Gao RK, Song XF, Zhan CB, Weng CG, Cheng S et al. Light trapping induced flexible wrinkled nanocone SERS substrate for highly sensitive explosive detection. Sens Actuators B: Chem 314, 128081 (2020).
71. Lee CH, Tian LM, Singamaneni S. Paper-based SERS swab for rapid trace detection on real-world surfaces. ACS Appl Mater Interfaces 2, 3429-3435 (2010).

72. Yu WW, White IM. Chromatographic separation and detection of target analytes from complex samples using inkjet printed SERS substrates. Analyst 138, 3679-3686 (2013).

73. Polavarapu L, Porta AL, Novikov SM, Coronado-Puchau M, Liz-Marzán ML. Pen on paper approach toward the design of universal surface enhanced Raman scattering substrates. Small 10, 3065-3071 (2014).

74. Lan LL, Hou XY, Gao YM, Fan XC, Qiu T. Inkjet-printed paperbased semiconducting substrates for surface-enhanced Raman spectroscopy. Nanotechnology 31, 055502 (2020).

75. Chamuah N, Hazarika A, Hatiboruah D, Nath P. SERS on paper: an extremely low cost technique to measure Raman signal. J Phys D: Appl Phys 50, 485601 (2017).

76. Yu CC, Chou SY, Tseng YC, Tseng SC, Yen YT et al. Singleshot laser treatment provides quasi-three-dimensional paperbased substrates for SERS with attomolar sensitivity. Nanoscale 7, 1667-1677 (2015).

77. Zhang $R, X u B B$, Liu $X Q$, Zhang $Y L, X u ~ Y$ et al. Highly efficient SERS test strips. Chem Commun 48, 5913-5915 (2012).

78. Raza A, Saha B. In situ silver nanoparticles synthesis in agarose film supported on filter paper and its application as highly efficient SERS test stripes. Forensic Sci Int 237, e42-e46 (2014).

79. Das D, Senapati S, Nanda KK. "Rinse, Repeat": an efficient and reusable SERS and catalytic platform fabricated by controlled deposition of silver nanoparticles on cellulose paper. ACS Sustainable Chem Eng 7, 14089-14101 (2019).

80. Oliveira MJ, Quaresma P, de Almeida MP, Araújo A, Pereira E et al. Office paper decorated with silver nanostars - an alternative cost effective platform for trace analyte detection by SERS. Sci Rep 7, 2480 (2017).

81. Yu WW, White IM. Inkjet printed surface enhanced Raman spectroscopy array on cellulose paper. Anal Chem $\mathbf{8 2}$, 9626-9630 (2010).

82. Li YX, Zhang $\mathrm{K}$, Zhao JJ, Ji J, Ji C et al. A three dimensional silver nanoparticles decorated plasmonic paper strip for SERS detection of low-abundance molecules. Talanta 147, 493-500 (2016).

83. Marques PAAP, Nogueira HIS, Pinto RJB, Neto CP, Trindade T. Silver - bacterial cellulosic sponges as active SERS substrates. J Raman Spectrosc 39, 439-443 (2008).

84. Kim W, Kim YH, Park HK, Choi S. Facile fabrication of a silver nanoparticle immersed, surface-enhanced Raman scattering imposed paper platform through successive ionic layer absorption and reaction for on-site bioassays. ACS Appl Mater Interfaces 7, 27910-27917 (2015).

85. Hasi WLJ, Lin X, Lou XT, Lin S, Yang F et al. Chloride ion assisted self assembly of silver nanoparticles on filter paper as SERS substrate. Appl Phys A 118, 799-807 (2015).

86. Huang ZF, Cao G, Sun Y, Du SR, Li YZ et al. Evaluation and optimization of paper-based SERS substrate for potential label-free Raman analysis of seminal plasma. I Nanomater 2017, 4807064 (2017).

87. Mehn D, Morasso C, Vanna R, Bedoni M, Prosperi D et al. Immobilised gold nanostars in a paper-based test system for surface-enhanced Raman spectroscopy. Vib Spectrosc 68, 45-50 (2013). 
88. Wang C, Liu BX, Dou XC. Silver nanotriangles-loaded filter paper for ultrasensitive SERS detection application benefited by interspacing of sharp edges. Sens Actuators B: Chem 231, 357-364 (2016).

89. Lee $\mathrm{CH}$, Hankus ME, Tian LM, Pellegrino PM, Singamaneni S. Highly sensitive surface enhanced Raman scattering substrates based on filter paper loaded with plasmonic nanostructures. Anal Chem 83, 8953-8958 (2011).

90. Hoppmann EP, Yu WW, White IM. Highly sensitive and flexible inkjet printed SERS sensors on paper. Methods 63, 219-224 (2013).

91. Hoppmann EP, Yu WW, White IM. Inkjet-printed fluidic paper devices for chemical and biological analytics using surface enhanced Raman spectroscopy. IEEE J Sel Top Quantum Electron 20, 7300510 (2014).

92. Kim D, Gwon G, Lee G, Jeon Y, Kim UJ et al. Surface enhanced Raman scattering active AuNR array cellulose films for multi hazard detection. J Hazard Mater 402, 123505 (2021).

93. Xian L, You RY, Lu DC, Wu CJ, Feng SY et al. Surface-modified paper-based SERS substrates for direct-droplet quantitative determination of trace substances. Cellulose 27, 1483-1495 (2020).

94. Moram SSB, Byram C, Shibu SN, Chilukamarri BM, Soma VR. $\mathrm{Ag} / \mathrm{Au}$ nanoparticle-loaded paper-based versatile surface-enhanced Raman spectroscopy substrates for multiple explosives detection. ACS Omega 3, 8190-8201 (2018).

95. Lin S, Hasi W, Han SQGW, Lin X, Wang L. A dual-functional PDMS-assisted paper-based SERS platform for the reliable detection of thiram residue both on fruit surfaces and in juice. Anal Methods 12, 2571-2579 (2020).

96. Ming HZ, Zhang YZ, Kotaki M, Ramakrishna S. A review on polymer nanofibers by electrospinning and their applications in nanocomposites. Compos Sci Technol 63, 2223-2253 (2003).

97. Teo WE, Ramakrishna S. A review on electrospinning design and nanofibre assemblies. Nanotechnology 17, R89-R106 (2006).

98. Aleisa R. Electrospinning. In Handbook of Synthetic Methodologies and Protocols of Nanomaterials, Liu YD, He L, Yin YD edn, 149-181 (World Scientific, 2019); http://doi.org/10.1142/ 9789813277847 0006.

99. Husain O, Lau W, Edirisinghe M, Parhizkar M. Investigating the particle to fibre transition threshold during electrohydrodynamic atomization of a polymer solution. Mater Sci Eng: C 65, 240-250 (2016).

100. Wan MH, Zhao HD, Peng LC, Zou XY, Zhao YB et al. Loading of $\mathrm{Au} / \mathrm{Ag}$ bimetallic nanoparticles within and outside of the flexible $\mathrm{SiO}_{2}$ electrospun nanofibers as highly sensitive, stable, repeatable substrates for versatile and trace SERS detection. Polymers 12, 3008 (2020).

101. Zhang ZJ, Wu YP, Wang ZH, Zou XY, Zhao YB et al. Fabrication of silver nanoparticles embedded into polyvinyl alcohol (Ag/PVA) composite nanofibrous films through electrospinning for antibacterial and surface-enhanced Raman scattering (SERS) activities. Mater Sci Eng: C 69, 462-469 (2016).

102. Jalaja K, Bhuvaneswari S, Ganiga M, Divyamol R, Anup S et al. Effective SERS detection using a flexible wiping substrate based on electrospun polystyrene nanofibers. Anal Methods $\mathbf{9}$, 3998-4003 (2017).

103. Jia $P$, Chang J, Wang JQ, Zhang $P$, Cao B et al. Fabrication and formation mechanism of $\mathrm{Ag}$ nanoplate - decorated nan- ofiber mats and their application in SERS. Chem-Asian $J \mathbf{1 1}$, 86-92 (2016).

104. Chamuah N, Bhuyan N, Das PP, Ojah N, Choudhary AJ et al. Gold-coated electrospun PVA nanofibers as SERS substrate for detection of pesticides. Sens Actuators B: Chem 273 , 710-717 (2018).

105. Motamedi AS, Mirzadeh $\mathrm{H}$, Hajiesmaeilbaigi $\mathrm{F}$, BagheriKhoulenjani S, Shokrgozar MA. Piezoelectric electrospun nanocomposite comprising Au NPs/PVDF for nerve tissue engineering. J Biomed Mater Res Part A 105, 1984-1993 (2017).

106. Zhang CL, Lv KP, Cong HP, Yu SH. Controlled assemblies of gold nanorods in PVA nanofiber matrix as flexible free - standing SERS substrates by electrospinning. Small 8, 648-653 (2012).

107. Zhang LF, Gong X, Bao Y, Zhao Y, Xi M et al. Electrospun nanofibrous membranes surface-decorated with silver nanoparticles as flexible and active/sensitive substrates for surfaceenhanced Raman scattering. Langmuir 28, 14433-14440 (2012).

108. Alyami A, Quinn AJ, lacopino D. Flexible and transparent Surface Enhanced Raman Scattering (SERS)-Active $\mathrm{Ag}$ NPs/PDMS composites for in-situ detection of food contaminants. Talanta 201, 58-64 (2019).

109. Qiu HW, Wang MQ, Jiang SZ, Zhang L, Yang Z et al. Reliable molecular trace-detection based on flexible SERS substrate of graphene/Ag-nanoflowers/PMMA. Sens Actuators B: Chem 249, 439-450 (2017).

110. Zuo ZW, Zhu K, Gu C, Wen YB, Cui GL et al. Transparent, flexible surface enhanced Raman scattering substrates based on Ag coated structured PET (polyethylene terephthalate) for in-situ detection. Appl Surf Sci 379, 66-72 (2016).

111. Creedon NC, Lovera P, Furey A, O'Riordan A. Transparent polymer-based SERS substrates templated by a soda can. Sens Actuators B: Chem 259, 64-74 (2018).

112. Alvarez-Ruiz DT, Almohammed S, Fularz A, Barwich ST, Rice $\mathrm{JH}$. Self-energized organic-inorganic hybrid composite for surface enhanced Raman spectroscopy. J Appl Phys 129, 193102 (2021).

113. Wang KQ, Sun DW, Pu HB, Wei QY. Polymer multilayers enabled stable and flexible Au@Ag nanoparticle array for nondestructive SERS detection of pesticide residues. Talanta 223, 121782 (2021)

114. Zhang CP, Yi PY, Peng LF, Lai XM, Chen J et al. Continuous fabrication of nanostructure arrays for flexible surface enhanced Raman scattering substrate. Sci Rep 7, 39814 (2017).

115. Fang LN, Li JC, Zhang JR, Han DD. Femtosecond laser structuring for flexible surface-enhanced Raman spectroscopy substrates. IEEE Photonics J 13, 6800908 (2021).

116. Byram C, Moram SSB, Soma VR. SERS based detection of multiple analytes from dye/explosive mixtures using picosecond laser fabricated gold nanoparticles and nanostructures. Analyst 144, 2327-2336 (2019).

117. Naqvi TK, Bajpai A, Bharati MSS, Kulkarni MM, Siddiqui AM et al. Ultra-sensitive reusable SERS sensor for multiple hazardous materials detection on single platform. J Hazard Mater 407, 124353 (2021)

118. Byram C, Moram SSB, Soma VR. Picosecond laser fabricated $\mathrm{Ag}, \mathrm{Au}$ and $\mathrm{Ag}-\mathrm{Au}$ nanoparticles for detecting ammonium perchlorate using a portable Raman spectrometer. AIP Conf Proc 1942, 050028 (2018). 
119. Hamad S, Moram SSB, Yendeti B, Podagatlapalli GK, Rao SVSN et al. Femtosecond laser-induced, nanoparticle-embedded periodic surface structures on crystalline silicon for reproducible and multi-utility SERS platforms. ACS Omega 3, 18420-18432 (2018).

120. Moram SSB, Shaik AK, Byram C, Hamad S, Soma VR. Instantaneous trace detection of nitro-explosives and mixtures with nanotextured silicon decorated with $\mathrm{Ag}-\mathrm{Au}$ alloy nanoparticles using the SERS technique. Anal Chim Acta 1101, 157-168 (2020).

121. Podagatlapalli GK, Hamad S, Mohiddon MA, Rao SV. Effect of oblique incidence on silver nanomaterials fabricated in water via ultrafast laser ablation for photonics and explosives detection. Appl Surf Sci 303, 217-232 (2014).

122. Tang B, Wang JF, Xu SP, Afrin T, Xu WQ et al. Application of anisotropic silver nanoparticles: multifunctionalization of wool fabric. J Colloid Interface Sci 356, 513-518 (2011).

123. Liu J, Zhou J, Tang B, Zeng T, Li YL et al. Surface enhanced Raman scattering (SERS) fabrics for trace analysis. App/ Surf Sci 386, 296-302 (2016).

124. Chen YM, Ge FY, Guang SY, Cai ZS. Low-cost and largescale flexible SERS-cotton fabric as a wipe substrate for surface trace analysis. App/ Surf Sci 436, 111-116 (2018).

125. Zheng YD, Xiao MD, Jiang SX, Ding F, Wang JF. Coating fabrics with gold nanorods for colouring, UV-protection, and antibacterial functions. Nanoscale 5, 788-795 (2013).

126. Wang $\mathrm{RH}$, Wang $\mathrm{XW}$, Xin JH. Advanced visible-light-driven self-cleaning cotton by $\mathrm{Au} / \mathrm{TiO}_{2} / \mathrm{SiO}_{2}$ photocatalysts. ACS Appl Mater Interfaces 2, 82-85 (2010).

127. Gao W, Xu JT, Cheng C, Quu S, Jiang SX. Rapid and highly sensitive SERS detection of fungicide based on flexible "wash free" metallic textile. Appl Surf Sci 512, 144693 (2020).

128. Lu SC, You TT, Yang N, Gao YK, Yin PG. Flexible SERS substrate based on $\mathrm{Ag}$ nanodendrite-coated carbon fiber cloth: simultaneous detection for multiple pesticides in liquid droplet. Anal Bioanal Chem 412, 1159-1167 (2020).

129. Zhang ZL, Si TT, Liu J, Zhou GW. In-situ grown silver nanoparticles on nonwoven fabrics based on mussel-inspired polydopamine for highly sensitive SERS Carbaryl pesticides detection. Nanomaterials 9, 384 (2019).

130. Liu Y, Zhang Y, Tardivel M, Lequeux M, Chen XP et al. Evaluation of the reliability of six commercial SERS substrates. Plasmonics 15, 743-752 (2020).

131. Hakonen A, Wu KY, Schmidt MS, Andersson PO, Boisen A et al. Detecting forensic substances using commercially available SERS substrates and handheld Raman spectrometers. Talanta 189, 649-652 (2018).

132. Wang JP, Yang L, Liu BH, Jiang HH, Liu RY et al. Inkjet-printed silver nanoparticle paper detects airborne species from crystalline explosives and their ultratrace residues in open environment. Anal Chem 86, 3338-3345 (2014).

133. Moram SSB, Byram C, Soma VR. Gold-nanoparticle-and nanostar-loaded paper-based SERS substrates for sensing nanogram-level Picric acid with a portable Raman spectrometer. Bull Mater Sci 43, 53 (2020).

134. Khan GA, Demirtaş Ö, Demir AK, Ayteki Ö, Bek A et al. Fabrication of flexible, cost-effective, and scalable silver substrates for efficient surface enhanced Raman spectroscopy based trace detection. Colloids Surf A: Physicochem Eng Aspects 619, 126542 (2021).
135. Yu WW, White IM. Inkjet-printed paper-based SERS dipsticks and swabs for trace chemical detection. Analyst $\mathbf{1 3 8}$ 1020-1025 (2013).

136. Alder R, Hong J, Chow E, Fang JH, Isa F et al. Application of plasma-printed paper-based SERS substrate for cocaine detection. Sensors 21, 810 (2021).

137. Zhang LZ, Liu J, Zhou GW, Zhang ZL. Controllable in-situ growth of silver nanoparticles on filter paper for flexible and highly sensitive SERS sensors for malachite green residue detection. Nanomaterials 10, 826 (2020).

138. Lee CW, Chia ZC, Hsieh YT, Tsai HC, Tai Y et al. A facile wetchemistry approach to engineer an Au-based SERS substrate and enhance sensitivity down to ppb-level detection. Nanoscale 13, 3991-3999 (2021).

139. Zhu YQ, Li MQ, Yu DY, Yang LB. A novel paper rag as 'DSERS'substrate for detection of pesticide residues at various peels. Talanta 128, 117-124 (2014).

140. Bolz A, Panne U, Rurack K, Buurman M. Glass fibre paperbased test strips for sensitive SERS sensing. Anal Methods $\mathbf{8}$, 1313-1318 (2016).

141. Zhu JJ, Chen QS, Kutsanedzie FYH, Yang MX, Ouyang $Q$ et al. Highly sensitive and label-free determination of thiram residue using surface-enhanced Raman spectroscopy (SERS) coupled with paper-based microfluidics. Anal Methods 9, 6186-6193 (2017).

142. Ma YD, Wang YH, Luo Y, Duan HZ, Li D et al. Rapid and sensitive on-site detection of pesticide residues in fruits and vegetables using screen-printed paper-based SERS swabs. Anal Methods 10, 4655-4664 (2018).

143. Sun J, Gong L, Lu YT, Wang DM, Gong ZJ et al. Dual functional PDMS sponge SERS substrate for the on-site detection of pesticides both on fruit surfaces and in juice. Analyst 143, 2689-2695 (2018).

144. Kim D, Ko Y, Kwon G, Choo YM, You J. Low-cost, high-performance plasmonic nanocomposites for hazardous chemical detection using surface enhanced Raman scattering. Sens Actuators B: Chem 274, 30-36 (2018).

145. Luo W, Chen M, Hao NY, Huang $X Q$, Zhao $X Y$ et al. In situ synthesis of gold nanoparticles on pseudo-paper films as flexible SERS substrate for sensitive detection of surface organic residues. Talanta 197, 225-233 (2019).

146. Atanasov PA, Nedyalkov NN, Fukata N, Jevasuwan W, Subramani $T$ et al. Surface-enhanced Raman spectroscopy (SERS) of mancozeb and thiamethoxam assisted by gold and silver nanostructures produced by laser techniques on paper. Appl Spectros 73, 313-319 (2019).

147. Zhang CM, You TT, Yang N, Gao YK, Jiang L et al. Hydrophobic paper-based SERS platform for direct-droplet quantitative determination of melamine. Food Chem 287, 363-368 (2019).

148. Xie J, Li LY, Khan IM, Wang ZP, Ma XY. Flexible paper-based SERS substrate strategy for rapid detection of methyl parathion on the surface of fruit. Spectrochim Acta Part A: Mol Biomol Spectrosc 231, 118104 (2020).

149. Chen J, Huang MZ, Kong LL. Flexible Ag/nanocellulose fibers SERS substrate and its applications for in-situ hazardous residues detection on food. App/ Surf Sci 533, 147454 (2020).

150. Sun L, Yu ZL, Alsammarraie FK, Lin MH, Kong FB et al. Development of cellulose nanofiber-based substrates for rapid detection of ferbam in kale by surface-enhanced Raman spectro- 
scopy. Food Chem 347, 129023 (2021).

151. Song SW, Kim D, Kim J, You J, Kim HM. Flexible nanocellulose-based SERS substrates for fast analysis of hazardous materials by spiral scanning. J Hazard Mater 414, 125160 (2021).

152. Tay LL, Poirier S, Ghaemi A, Hulse J, Wang SL. Paper-based surface-enhanced Raman spectroscopy sensors for field applications. J Raman Spectros 52, 563-572 (2021).

153. Lee HG, Choi W, Yang SY, Kim DH, Park SG et al. PCRcoupled Paper-based surface-enhanced Raman scattering (SERS) sensor for rapid and sensitive detection of respiratory bacterial DNA. Sens Actuators B: Chem 326, 128802 (2021).

154. Kim D, Kim J, Henzie J, Ko Y, Lim H et al. Mesoporous Au films assembled on flexible cellulose nanopaper as high-performance SERS substrates. Chem Eng J 419, 129445 (2021).

155. Xu XY, Hu XM, Fu FY, Liu L, Liu XD. DNA-induced assembly of silver nanoparticle decorated cellulose nanofiber: a flexible surface-enhanced Raman spectroscopy substrate for the selective charge molecular detection and wipe test of pesticide residues in fruits. ACS Sustainable Chem Eng 9, 5217-5229 (2021).

156. Gong ZJ, Du HJ, Cheng FS, Wang C, Wang CC et al. Fabrication of SERS swab for direct detection of trace explosives in fingerprints. ACS Appl Mater Interfaces 6, 21931-21937 (2014).

157. Wang C, Wong KW, Wang Q, Zhou YF, Tang CY et al. Silvernanoparticles-loaded chitosan foam as a flexible SERS substrate for active collecting analytes from both solid surface and solution. Talanta 191, 241-247 (2019).

158. Kong LL, Huang MZ, Chen J, Lin MS. Fabrication of sensitive silver-decorated cotton swabs for SERS quantitative detection of mixed pesticide residues in bitter gourds. New J Chem $\mathbf{4 4}$, 12779-12784 (2020).

159. Liu J, Si TT, Zhang ZL. Mussel-inspired immobilization of silver nanoparticles toward sponge for rapid swabbing extraction and SERS detection of trace inorganic explosives. Talanta 204, 189-197 (2019).

160. Bharati MSS, Byram C, Banerjee D, Sarma D, Barkakaty B et al. Gold nanoparticle nanofibres as SERS substrate for detection of methylene blue and a chemical warfare simulant (methyl salicylate). Bull Mater Sci 14, 103 (2021).

161. Chen Y, Cao JL, Wei HY, Wu ZG, Wang XP et al. Synthesis of polyvinyl alcohol/Ag electrospun nanofibers as highly efficient flexible SERS substrates. Vib Spectrosc 114, 103246 (2021).

162. Kong LS, Dong NX, Tian GF, Qi SL, Wu DZ. Highly enhanced Raman scattering with good reproducibility observed on a flexible PI nanofabric substrate decorated by silver nanoparticles with controlled size. App/ Surf Sci 511, 145443 (2020).

163. Cai LM, Deng Z, Dong J, Song SD, Wang YR et al. Fabrication of non-woven fabric-based SERS substrate for direct detection of pesticide residues in fruits. J Anal Test 1, 322-329 (2017).

164. Cheng DS, He MT, Ran JH, Cai GM, Wu JH et al. Depositing a flexible substrate of triangular silver nanoplates onto cotton fabrics for sensitive SERS detection. Sens Actuators B: Chem 270, 508-517 (2018).

165. Cheng DS, Bai X, He MT, Wu JH, Yang HJ et al. Polydopamine-assisted immobilization of Ag@AuNPs on cotton fabrics for sensitive and responsive SERS detection. Cellulose 26, 4191-4204 (2019).
166. Bian XY, Xu JT, Yang J, Chiu KI, Jiang SX. Flexible Ag SERS substrate for non-destructive and rapid detection of toxic materials on irregular surface. Surf Interfaces 23, 100995 (2021).

167. Zheng WW, Tian WT, Liu XJ, Zhang $Q Q$, Zong $\mathrm{CH}$ et al. In situ photochemical deposition of $\mathrm{Ag}$ nanoparticles on polyester fiber membranes as flexible SERS substrates for sensitive detection of sodium saccharin in soft drinks. Microchem J 164, 106003 (2021).

168. Tian XR, Zhai P, Guo JQ, Yu Q, Xu LZ et al. Fabrication of plasmonic cotton gauze-Ag composite as versatile SERS substrate for detection of pesticides residue. Spectrochim Acta Part A: Mol Biomol Spectrosc 257, 119766 (2021).

169. Liu AR, Zhang S, Guang SY, Ge FY, Wang J. Ag-coated nylon fabrics as flexible substrates for surface-enhanced Raman scattering swabbing applications. J Mater Res 35, 1271-1278 (2020).

170. Ning S, Wang ZK, Mu J, Jie Z. Flexible carbon fiber cloth decorated by $\mathrm{Ag}$ nanoparticles for high Raman enhancement. Opt Mater Express 11, 1321-1333 (2021).

171. Sun MM, Qian HM, Liu J, Li YC, Pang SP et al. A flexible conductive film prepared by the oriented stacking of $\mathrm{Ag}$ and $\mathrm{Au} / \mathrm{Ag}$ alloy nanoplates and its chemically roughened surface for explosive SERS detection and cell adhesion. RSC Adv 7, 7073-7078 (2017).

172. Gupta P, Luan JY, Wang ZY, Cao SS, Bae SH et al. On-demand electromagnetic hotspot generation in surface-enhanced Raman scattering substrates via "add-on" plasmonic patch. ACS Appl Mater Interfaces 11, 37939-37946 (2019).

173. Emamian S, Eshkeiti A, Narakathu BB, Avuthu SGR, Atashbar MZ. Gravure printed flexible surface enhanced Raman spectroscopy (SERS) substrate for detection of 2,4-dinitrotoluene (DNT) vapor. Sens Actuators B: Chem 217, 129-135 (2015).

174. Liu W, Song ZH, Zhao YF, Liu Y, He X et al. Flexible porous aerogels decorated with $\mathrm{Ag}$ nanoparticles as an effective SERS substrate for label-free trace explosives detection. Anal Methods 12, 4123-4129 (2020).

175. Gao RK, Qian HY, Weng CG, Wang XL, Xie C et al. A SERS stamp: multiscale coupling effect of silver nanoparticles and highly ordered nano-micro hierarchical substrates for ultrasensitive explosive detection. Sens Actuators B: Chem 321, 128543 (2020).

176. Xu KC, Wang ZY, Tan CF, Kang N, Chen LW et al. Uniaxially stretched flexible surface plasmon resonance film for versatile surface enhanced Raman scattering diagnostics. ACS Appl Mater Interfaces 9, 26341-26349 (2017).

177. Li CH, Xu SC, Yu J, Jiang SZ, Liu AH et al. 3D hybrid $\mathrm{MoS}_{2} /$ AgNPs/inverted pyramid PMMA resonant cavity system for the excellent flexible surface enhanced Raman scattering sensor. Sens Actuators B: Chem 274, 152-162 (2018).

178. Xiu XW, Guo Y, Li CH, Li Z, Li DZ et al. High-performance 3D flexible SERS substrate based on graphene oxide/silver nanoparticles/pyramid PMMA. Opt Mater Express 8, 844-857 (2018).

179. Zang SY, Liu H, Wang Q, Yang JW, Pang ZQ et al. Facile fabrication of $\mathrm{Au}$ nanoworms covered polyethylene terephthalate (PET) film: towards flexible SERS substrates. Mater Lett 294, 129643 (2021).

180. Li Y, Xin XL, Zhang TT, Li WH, Li JS et al. Raspberry like polyamide@ Ag hybrid nanoarrays with flexible cores and SERS 
signal enhancement strategy for adenosine detection. Chem Eng J 422, 129983 (2021).

181. Chen JM, Huang YJ, Kannan P, Zhang L, Lin ZY et al. Flexible and adhesive surface enhance Raman scattering active tape for rapid detection of pesticide residues in fruits and vegetables. Anal Chem 88, 2149-2155 (2016).

182. Wei W, Du YX, Zhang LM, Yang Y, Gao YF. Improving SERS hot spots for on-site pesticide detection by combining silver nanoparticles with nanowires. J Mater Chem C 6, 8793-8803 (2018).

183. Ma Y, Chen Y, Tian YR, Gu CJ, Jiang T. Contrastive study of in situ sensing and swabbing detection based on SERS-active gold nanobush-PDMS hybrid film. J Agric Food Chem 69, 1975-1983 (2021).

184. Xu LM, Liu HG, Hui Z, Hong MH. One-step fabrication of metal nanoparticles on polymer film by femtosecond LIPAA method for SERS detection. Talanta 228, 122204 (2021).

185. Sitjar J, Liao JD, Lee H, Pan LP, Liu BH et al. Ag nanostructures with spikes on adhesive tape as a flexible sers-active substrate for in situ trace detection of pesticides on fruit skin. Nanomaterials 9, 1750 (2019).

186. https://www.stellarnet.us/spectrometers-accessories/sers-substrates/.

187. https://www.horiba.com/en_en/products/detail/action/show/Pro duct/sers-substrates-1635/.

188. https://www.sersitive.eu/.

189. http://enspectr.com/applications/sers-analysis/

190. https://www.silmeco.com/products/sers-substrate-serstrate/.

191. https://www.hamamatsu.com/jp/en/product/optical-components/sers-substrate/index.html.

192. https://integratedoptics.com/products/sers-substrates.

193. https://www.trademed.com/products/6451/SERS-Substrates.html.

194. http://www.madatec.com/RAMAN_files/Q-SERS\%20G1_data\% 20sheet-Madatec.pdf.

195. https://www.metrohm.com/en/products/607506170.

196. Langer J, de Aberasturi DJ, Aizpurua J, Alvarez-Puebla RA, Auguié $B$ et al. Present and future of surface-enhanced Raman scattering. ACS Nano 14, 28-117 (2020).

197. Goodacre R, Graham D, Faulds, K. Recent developments in quantitative SERS: Moving towards absolute quantification. Trends Anal Chem 102, 359-368 (2018).

198. Szaniawska A, Kudelski A. Applications of Surface-Enhanced Raman Scattering in Biochemical and Medical Analysis. Front Chem 9, 664134 (2021).

199. Cupil-Garcia V, Strobbia P, Crawford BM, Wang HN, Ngo H et al. Plasmonic nanoplatforms: from surface - enhanced Raman scattering sensing to biomedical applications. J Raman Spectros 52, 541-553 (2021).

200. Lin L, Bi XY, Gu YQ, Wang F, Ye J. Surface-enhanced Raman scattering nanotags for bioimaging. J Appl Phys 129,
191101 (2021)

201. Jiang L, Hassan MM, Ali S, Li HH, Sheng R et al. Evolving trends in SERS-based techniques for food quality and safety: a review. Trends Food Sci Technol 112, 225-240 (2021).

202. Yadav S, Sadique MA, Ranjan P, Kumar N, Singhal A et al. SERS based lateral flow immunoassay for point-of-care detection of SARS-CoV-2 in clinical samples. ACS Appl Bio Mater 4 2974-2995 (2021).

203. Chen H, Park SG, Choi N, Kwon HJ, Kang T et al. Sensitive detection of SARS-CoV-2 using a SERS-based aptasensor. ACS Sens 6, 2378-2385 (2021).

204. Weng SZ, Hu XJ, Wang JH, Tang L, Li P et al. Advanced application of Raman spectroscopy and surface-enhanced Raman spectroscopy in plant disease diagnostics: a review. J Agric Food Chem 69, 2950-2964 (2021).

205. Amin MO, Al-Hetlani E, Lednev IK. Trends in vibrational spectroscopy offingermarks for forensicpurposes. Trends Anal Chem 143, 116341 (2021).

206. Betz JF, Yu WW, Cheng Y, White IM, Rubloff GW. Simple SERS substrates: powerful, portable, and full of potential. Phys Chem Chem Phys 16, 2224-2239 (2014).

207. Schlücker S. Surface-enhanced Raman spectroscopy: concepts and chemical applications. Angew Chem Int Ed $\mathbf{5 3}$, 4756-4795 (2014).

208. Yadav S, Satija J. The current state of the art of plasmonic nanofibrous mats as SERS substrates: design, fabrication and sensor applications. J Mater Chem B 9, 267-282 (2021).

209. Bharati MSS, Chandu B, Banerjee D, Sarma D, Barkakaty B, Venugopal Rao S. Gold Nanoparticle Nanofibers as SERS Substrate for Detection of Methylene Blue and a Chemical Warfare Simulant (Methyl Salicylate). Bull Mater Sci 44, 103 (2021).

\section{Acknowledgements}

V. R. Soma thanks the constant support, encouragement of the Director, ACRHEM (UoH); Dr. A. K. Razdan and Dr. Vijayeta Gambhir (LASTEC, India). We are grateful for financial supports from DRDO, India, for funding [Project \#ERIP/ER/1501138/M/01/319/D(R\&D) dated 27.02.2017]. V. R. Soma thanks University of Hyderabad for support through the Institute of Eminence (IoE) project UOH/IOE/RC1/RC1-2016. The IoE grant was obtained vide notification F11/9/2019-U3(A) from the MHRD, India. V.R. Soma thanks DST for support through project \#CRG/2019/003714 dated 31 January 2020 .

\section{Author contributions}

M. S. S. Bharati and V. R. Soma both contributed equally to this review.

\section{Competing interests}

The authors declare no competing financial interests. 